\title{
A THEORY OF HOUSING DEMAND SHOCKS
}

\author{
ZHENG LIU, PENGFEI WANG, AND TAO ZHA
}

\begin{abstract}
Housing demand shocks are an important source of housing price fluctuations and, through the collateral channel, they drive macroeconomic fluctuations as well. However, these reduced-form shocks in the standard macro models fail to generate the observed large fluctuations in the housing price-to-rent ratio. We build a tractable heterogeneous-agent model that provides a microeconomic foundation for housing demand shocks. Households with high marginal utility of housing face binding credit constraints, giving rise to a liquidity premium in the aggregated housing Euler equation. The liquidity premium drives a wedge between the house price and the average rent and allows credit supply shocks to generate large fluctuations in house prices and the price-to-rent ratio.
\end{abstract}

\section{INTRODUCTION}

Since the global financial crisis of 2008-09, many studies have shown that financial factors have important interactions with the macro economy and, from a policy perspective, financial stability is important for achieving macro stability. ${ }^{1}$ The financial crisis was triggered by a collapse of the U.S. housing market. But what triggered the sharp declines in house prices?

The empirical macro literature suggests that a housing demand shock is the primary driving force for house prices. Working through the collateral channel, such shocks also drive a large fraction of business cycle fluctuations (Iacoviello and Neri, 2010; Liu et al., 2013). In these standard macroeconomic models, housing demand shocks are proxied by shifts in the representative agent's tastes for housing. Such taste shifts are of reduced form without explicit microeconomic foundations. A housing demand

Date: January 9, 2019.

JEL classification: E21, E27, E32.

Liu: Federal Reserve Bank of San Francisco; Email: zliu001@gmail.com. Wang: Hong Kong University of Science and Technology; Email: pfwanghkust@gmail.com. Zha: Federal Reserve Bank of Atlanta, Emory University, and NBER; Email: zmail@tzha.net. The views expressed herein are those of the authors and do not necessarily reflect the views of the Federal Reserve Banks of Atlanta and San Francisco or the Federal Reserve System.

${ }^{1}$ See Gertler and Gilchrist (2018) for a survey of the recent literature. 
shock drives fluctuations in the house price through fluctuations in the implicit rent, implying counterfactually large volatilities of rents.

In the data, however, house prices fluctuate much more than rents, and the priceto-rent ratio is highly volatile and strongly comoves with house prices. These patterns are observed not only in the United States (Figure 1), but also in the other OECD countries (Figure 2). The puzzle is then: Why does the price-to-rent ratio fluctuate so much?

This paper presents a tractable heterogeneous-agent model that builds a microeconomic foundation for housing demand shocks and provides an explanation for the observed large fluctuations in the price-to-rent ratio.

Our baseline model features a large number of household members, each facing an idiosyncratic shock to their marginal utility of housing. In the decentralized housing markets, members finance house purchases with both internal funds and external debts, and external financing is subject to collateral constraints. For a given loanto-value ratio, there exists a cutoff point in the support of the idiosyncratic shock distribution such that those agents with marginal utility of housing above the cutoff face binding collateral constraints, whereas those below the cutoff are unconstrained. The cutoff point is endogenous. It depends on the distribution of the idiosyncratic shocks and it varies with changes in macroeconomic conditions, and in particular, changes in credit supply conditions measured by the loan-to-value ratio.

In our model, the house price is determined by the the marginal rates of substitution (MRS) between housing and non-housing consumption for the marginal agent, who has an idiosyncratic shock at the cutoff level. Since credit-constrained agents have higher marginal utility than unconstrained agents, the marginal agent has the lowest MRS among all constrained agent. A credit supply expansion not only changes the identity of the marginal agent (the extensive margin), but also changes the quantity of house purchases by the new marginal agent (the intensive margin). In particular, an increase in credit supply makes some agents with high MRS who were initially credit-constrained to become unconstrained. Thus, the new marginal agent has a higher MRS, and this extensive margin of adjustments tends to raise the house price. However, an increase in credit supply also reallocates more houses to the new marginal agent, reducing the agent's MRS because of diminishing marginal utility. The relative strength of the two opposing effects depends on the size of the risk aversion parameter with respect to housing services. If housing risk version is greater than one, then the diminishing marginal utility effect dominates, and an increase in leverage reduces the 
marginal agent's MRS and the house price. If housing risk aversion is lower than one, then the opposite is true, and an increase in leverage raises the house price. If housing risk aversion equals one, then the two effects exactly offset and the house price is invariant to changes in leverage.

With plausible housing risk aversion (less than one), a credit supply expansion raises the house price. However, it does not have a direct impact on rent because heterogeneity in the marginal utility of housing and credit constraints give rise to a wedge between the house price and rent. Aggregating the housing Euler equations across all agents reveals that the equilibrium house price depends on the present values of two components: (1) an implicit rent corresponding to the average MRS across all agents; and (2) a liquidity premium that arises from binding collateral constraints for the subset of the agents with high marginal utility of housing services. The liquidity premium drives a wedge between the house price and the rent, creating room for the price-to-rent ratio to fluctuate in response to shocks to credit supply conditions. Furthermore, aggregation results in a mapping between the reduced-form aggregate housing demand shock in the representative-agent model and the sum of the implicit rent and the liquidity premium in the heterogeneous-agent model. This mapping provides a microeconomic foundation for housing demand shocks.

We examine the model's propagation mechanism based on both analytical solutions and numerical simulations. We show that changes in credit supply (i.e., the loan-tovalue ratio) underpin the reduced-form housing demand shocks. Importantly, the model is able to generate large fluctuations in both the house pricer and the price-torent ratio, in line with the data.

Our model's mechanism is consistent with empirical evidence. Following the approach of Mian et al. (2017), we construct a credit supply shock based on booms in the ratio of household debt to GDP associated with low mortgage interest rate spreads. Using an unbalanced panel of 25 advanced economies for the period from 1965 to 2013, we show that an increase in the household debt-to-GDP ratio associated with low mortgage spreads is followed by significant and persistent increases in the house price, but it has no significant impact on the rent.

The theoretical link between credit supply expansions and house price increases highlighted in our model is also consistent with the empirical findings from other microeconomic studies. For example, Landvoigt et al. (2015) find that increased credit availability for poor households with low-end homes was a major driver of the house price boom in the early 2000s. Households with low-end homes have smaller 
houses and thus higher marginal utility of housing. In our model, agents with high marginal utility face binding credit constraints. An increase in credit supply turns some of the constrained agents into unconstrained, boosting aggregate housing demand and the house price. We argue that the high-marginal-utility agents in our model can be broadly interpreted as corresponding to those "poor households" who have smaller houses (with low-end homes). We formalize this argument in an alternative model setup, in which household heterogeneity stems from idiosyncratic income shocks, rather than preference shocks. In this alternative setup, aggregate housing demand and the house price are still driven by changes in credit availability, which directly affects the credit-constrained agents, corresponding to those who have low income realizations and thus high marginal utility of housing. ${ }^{2}$

Our study is closely related and complementary to two important contributions by Favilukis et al. (2016) and Kaplan et al. (2017), both studying the driving forces of house prices and the price-to-rent ratio in models with overlapping generations and incomplete markets. Favilukis et al. (2016) emphasize the importance of aggregate business cycle risks and wealth distribution driven by bequest heterogeneity in preferences for driving house price booms. Kaplan et al. (2017) argue that a shift in beliefs about future housing demand was a main driver of housing price movements and the price-to-rent ratio around the Great Recession. A more optimistic forecast of future housing demand raises current housing demand and thus the house price because the price is forward looking; but it has no effect on the current rent since no shocks have been materialized. In their model, unlike ours, changes in credit conditions do not generate large fluctuations in the price-to-rent ratio because those are materialized shocks, which affect both the price and the rent, similar to the implications of the stylized aggregate model of Liu et al. (2013). In our heterogeneous-agent model, changes in credit supply do drive large fluctuations in the price-to-rent ratio, because such changes shift the composition of credit-constrained agents and thus the liquidity premium.

In what follows, we present a simple representative-agent model in Section II to highlight the price-to-rent puzzle. We then present in Section III a heterogenousagent model with idiosyncratic shocks to tastes for housing services. In Section IV, we derive analytical characterizations of the equilibrium in the heterogeneous-agent model to show how changes in credit supply can drive aggregate housing demand

\footnotetext{
${ }^{2}$ For more empirical studies that point to the importance of credit supply shocks for housing boom-bust cycles, see the survey of Mian and Sufi (2018) and the references therein.
} 
and the price-to-rent ratio. We also present some empirical evidence that supports the model's mechanism. In Section V, we show that the main insights from our heterogeneous-agent model can be generalized to several alternative environments. We provide some concluding remarks in Section VI.

\section{A REPRESEntATIVE-AGENT BENCHMARK MODEL}

This section presents a stylized representative-agent model to illustrate the role of housing demand shocks in driving the house price. The model is intentionally kept simple to sharpen the exposition. In particular, we focus on an endowment economy such that housing prices do not interact with consumption and production. ${ }^{3}$

The economy has one unit of housing supply (think about land) and an exogenous endowment of $y_{t}$ units of consumption goods. The representative household has the expected utility function

$$
\mathbb{E} \sum_{t=0}^{\infty} \beta^{t}\left\{\log c_{t}+\varphi_{t} \frac{h_{t}^{1-\theta}}{1-\theta}\right\},
$$

where $c_{t}$ denotes consumption, $h_{t}$ denotes housing, $\varphi_{t}$ denotes a housing demand shock. The parameter $\beta \in(0,1)$ is the subjective discount factor and $\theta>0$ is a parameter that measures the curvature of the utility function with respect to housing. The term $\mathbb{E}$ is an expectation operator.

The household chooses consumption, new housing purchases, and holdings of a riskfree bond denoted by $b_{t}$ to maximize the utility function (1) subject to the flow of funds constraint

$$
c_{t}+q_{t}\left(h_{t}-h_{t-1}\right) \leq y_{t}+\frac{b_{t}}{R_{t}}-b_{t-1},
$$

where $q_{t}$ denotes the housing price and $R_{t}$ denotes the risk free interest rate, both are taken as given by the household. The initial bond holdings $b_{-1}$ and initial housing $h_{-1}$ are also taken as given.

The optimizing decisions lead to the Euler equation for housing

$$
\frac{q_{t}}{c_{t}}=\beta \mathbb{E}_{t} \frac{q_{t+1}}{c_{t+1}}+\varphi_{t} h_{t}^{-\theta}
$$

\footnotetext{
${ }^{3}$ The main insight about the importance of housing demand shocks for housing price fluctuations carries over to a more general environment with collateral constraints, as shown by Liu et al. (2013), provided that both constrained and unconstrained agents participate in the housing market. In the more general setup considered by Liu et al. (2013), the housing price needs to satisfy the housing Euler equations of both types of agents, and the Euler equation for the unconstrained agent (the saver) in that model is qualitatively identical to that of the representative agent in the model studied here.
} 
and for bond holdings

$$
1=\beta R_{t} \mathbb{E}_{t} \frac{c_{t}}{c_{t+1}}
$$

A competitive equilibrium consists of sequences of allocations $\left\{c_{t}, b_{t}, h_{t}\right\}$ and prices $\left\{q_{t}, R_{t}\right\}$ that satisfy the Euler equations (3) and (4) and clear the markets for goods, bond, and housing. In particular, these market clearing conditions are given by

$$
\begin{aligned}
c_{t} & =y_{t}, \\
b_{t} & =0, \\
h_{t} & =1 .
\end{aligned}
$$

The equilibrium housing price is pinned down by iterating the housing Euler equation (3) forward. With the goods and housing market clearing conditions imposed, the housing Euler equation (3) implies that

$$
\frac{q_{t}}{y_{t}}=\beta \mathbb{E}_{t} q_{t+1} \frac{1}{y_{t+1}}+\varphi_{t},
$$

Iterating forward, we obtain the equilibrium housing price

$$
q_{t}=y_{t}\left[\mathbb{E}_{t} \sum_{j=0}^{\infty} \beta^{j} \varphi_{t+j}\right] \text {. }
$$

The implicit (or shadow) rent is given by the household's marginal rate of substitution between housing and non-housing consumption, and it is given by

$$
r_{h t}=\varphi_{t} y_{t}
$$

Thus, the price-to-rent ratio is given by

$$
\frac{q_{t}}{r_{h t}}=\frac{1}{\varphi_{t}} \mathbb{E}_{t} \sum_{j=0}^{\infty} \beta^{j} \varphi_{t+j} .
$$

Since we observe much larger fluctuations in housing prices than in consumption or aggregate output, the housing price solution (9) reveals that the large volatility of housing prices stems primarily from shocks to housing demand $\left(\varphi_{t}\right)$. In this model, housing demand shocks drive not just the housing price fluctuations, but also rent fluctuations as is clear from Eq. (10). Thus, this representative agent model has difficulties in generating large volatilities in the price-to-rent ratio, which we call the "price-to-rent" puzzle.

To see this more clearly, consider the stationary process for the housing demand shock

$$
\hat{\varphi}_{t}=\rho \hat{\varphi}_{t-1}+e_{t},
$$


where $\hat{\varphi}_{t} \equiv \ln \frac{\varphi_{t}}{\varphi}$ denotes the log-deviations of the housing demand shock from steady state, and $e_{t}$ is a white noise innovation to the shock.

Log-linearizing the solution to the housing price in Eq. (9) around the deterministic steady state and imposing the shock process in Eq. (12), we obtain

$$
\hat{q}_{t}=\hat{y}_{t}+(1-\beta) \mathbb{E}_{t}\left[\sum_{j=0}^{\infty} \beta^{j} \hat{\varphi}_{t+j}\right]=\hat{y}_{t}+\frac{1-\beta}{1-\beta \rho} \hat{\varphi}_{t},
$$

where $\hat{y}_{t}$ is an exogenous endowment process.

The log-linearized solution to the rent is given by

$$
\hat{r}_{h t}=\hat{y}_{t}+\hat{\varphi}_{t}
$$

The log-linearized price-to-rent ratio is thus given by

$$
\hat{q}_{t}-\hat{r}_{h t}=-\frac{\beta(1-\rho)}{1-\beta \rho} \hat{\varphi}_{t}
$$

There are two counter-factual implications of this representative agent model. First, the model implies that the price-to-rent ratio falls when housing price rises, as shown by Eq. (15). In the data, the price-rent ratio are highly positively correlated with housing prices (see Figures 1 and 2).

Second, the model cannot generate larger volatility of housing prices relative to rents. To see this, assume that the endowment is constant so that $\hat{y}_{t}=0$. The model implies that

$$
\frac{\operatorname{STD}\left(\hat{q}_{t}\right)}{\operatorname{STD}\left(\hat{r}_{h t}\right)}=\frac{1-\beta}{1-\beta \rho}<1
$$

so that the housing price is less volatile than the rent, while the opposite is true in the data.

\section{A Heterogenous-Agent MOdel OF HOUSing DEMAND}

The representative-agent model fails to generate the observe large volatilities of the price-to-rent ratio, giving rise to a "price-to-rent" puzzle. This puzzle calls for a better understanding of the forces behind the reduced-form housing demand shock. We now present a microeconomic foundation for the housing demand shock by incorporating household-level heterogeneity in the model. We show that this heterogeneous-agent model can generate large volatilities in both housing prices and the price-to-rent ratio, and is thus able to resolve the price-rent puzzle.

To make our point clear, we study a simple heterogeneous-agent model with idiosyncratic shocks to households' tastes for housing. Such idiosyncratic shocks are meant to capture potential heterogeneity in households' desires to purchase a home 
for such reasons as job relocations, schooling choices, and health care needs. We simplify all other aspects of the model as much as possible. In particular, we postulate the existence of some implicit financial arrangements to insure non-housing consumption against idiosyncratic realizations of housing taste shocks. We also abstract from labor supply and capital investment decisions in this basic model. ${ }^{4}$

III.1. The model environment. Consider a large household family with a continuum of members. Each member faces an idiosyncratic shock $\varepsilon_{t}$ to her taste for housing, and the shock is an i.i.d. process (across members and across time) drawn from the distribution $F(\cdot)$.

Assuming complete insurance against non-housing consumption risks, all members enjoy the same consumption $c_{t}$. Housing services, however, must be indexed by $\varepsilon$. The expected utility function of the family is given by

$$
\mathbb{E}_{0} \sum_{t=0}^{\infty} \beta^{t}\left[\log c_{t}+\varphi \int_{0}^{\infty} \frac{\varepsilon_{t}\left[h_{t}\left(\varepsilon_{t}\right)\right]^{1-\theta}}{1-\theta} d F\left(\varepsilon_{t}\right)\right],
$$

where $h_{t}\left(\varepsilon_{t}\right)$ denotes housing (or land) held by the member with shock $\varepsilon_{t}$, and the parameter $\varphi$ measures the utility weight of housing. Here, we intentionally assume that $\varphi$ stays constant, so that there is no aggregate housing demand shock. The parameter $\theta \geq 0$ is the relative risk aversion parameter with respect to housing.

The resources available to the family in the beginning of period $t$ includes an exogenous labor income $y_{t}$ and the resale value of existing housing stocks carried over from $t-1$ by all members, after paying off the matured debt for all members. The household uses these resources to finance family consumption spending $c_{t}$, as well as transfers $a_{t}$ to be equally dispersed among family members for their housing purchases in the decentralized housing markets. Since housing services are perfectly tradable across all household members, there is a unique equilibrium price of housing, denoted by $q_{t}$.

The household family faces the budget constraint

$$
c_{t}+a_{t}=y_{t}+q_{t} \int h_{t-1}\left(\varepsilon_{t-1}\right) d F\left(\varepsilon_{t-1}\right)-\int b_{t-1}\left(\varepsilon_{t-1}\right) d F\left(\varepsilon_{t-1}\right) .
$$

In the decentralized housing markets, a member with idiosyncratic shock $\varepsilon_{t}$ finances his spending on new housing $q_{t} h_{t}\left(\varepsilon_{t}\right)$ using both internal funds $a_{t}$ received from the

\footnotetext{
${ }^{4}$ In Appendix A, we generalize the model to incorporate endogenous labor supply and capital investment decisions. There, we do not assume complete insurance against consumption risks. Instead, we follow Lagos and Wright (2005) and Wen (2009) and assume quasi-linear preferences, which help keep the analysis with heterogeneity tractable.
} 
family and external borrowing $b_{t}\left(\varepsilon_{t}\right)$ at the interest rate $R_{t}$. The flow-of-funds constraint for the household member $\varepsilon_{t}$ in the decentralized housing market is given by

$$
q_{t} h_{t}\left(\varepsilon_{t}\right) \leq a_{t}+\frac{b_{t}\left(\varepsilon_{t}\right)}{R_{t}} .
$$

As in Kiyotaki and Moore (1997), imperfect contract enforcement implies that the external debt cannot exceed a fraction of the collateral value. The member with $\varepsilon_{t}$ thus faces the collateral constraint

$$
\frac{b_{t}\left(\varepsilon_{t}\right)}{R_{t}} \leq \kappa_{t} q_{t} h_{t}\left(\varepsilon_{t}\right)
$$

where the loan-to-value ratio $\kappa_{t} \in[0,1]$ is exogenous and potentially time varying, representing shocks to credit conditions.

Finally, we impose a short-selling constraint on the housing stock, so that

$$
h_{t}\left(\varepsilon_{t}\right) \geq 0
$$

The extreme case with $\kappa_{t}=1$ corresponds to the situation with no borrowing constraints. To see this, combine the flow-of-funds constraint (19) and the collateral constraint (20) to get

$$
q_{t} h_{t}\left(\varepsilon_{t}\right) \leq \frac{a_{t}}{1-\kappa_{t}}
$$

Clearly, if $\kappa_{t} \rightarrow 1$, then the limit on housing spending approaches infinity. In what follows, we focus on the case with $\kappa_{t}<1$.

The family chooses $c_{t}$ and $a_{t}$ and each member with $\varepsilon_{t}$ chooses $h_{t}\left(\varepsilon_{t}\right)$ and $b_{t}\left(\varepsilon_{t}\right)$ to maximize the utility function (17), subject to the budget constraint (18), as well as the individual member's flow-of-funds constraint (19), borrowing constraint (20), and short-selling constraint (21). The initial values of $b_{-1}$ and $h_{-1}$ and the prices $q_{t}$ and $R_{t}$ are taken as given.

Denote by $\lambda_{t}, \eta_{t}\left(\varepsilon_{t}\right), \pi_{t}\left(\varepsilon_{t}\right)$ and $\mu_{t}\left(\varepsilon_{t}\right)$ the Lagrangian multiplers associated with the constraints (18), (19), (20), and (21) respectively. In the discussions below, we focus on the general case with $\theta>0$, so that the short-selling constraint (21) is not binding, implying that $\mu_{t}\left(\varepsilon_{t}\right)=0$. We will also discuss the special case with $\theta=0$ in Section IV.4.

The first order condition with respect to $c_{t}$ is given by

$$
\frac{1}{c_{t}}=\lambda_{t}
$$

The first order condition with respect to $a_{t}$ implies

$$
\lambda_{t}=\int \eta_{t}\left(\varepsilon_{t}\right) d F\left(\varepsilon_{t}\right)
$$


A marginal unit of goods transferred to individual members for housing purchases reduces family consumption by one unit and hence the utility cost is $\lambda_{t}$. The utitlity gain from this transfer is the shadow value of newly purchased housing (i.e., $\eta_{t}\left(\varepsilon_{t}\right)$ ) averaged across all members.

The first order condition with respect to $h_{t}\left(\varepsilon_{t}\right)$ yields

$$
\eta_{t}\left(\varepsilon_{t}\right) q_{t}=\varphi \varepsilon_{t}\left[h_{t}\left(\varepsilon_{t}\right)\right]^{-\theta}+\beta \mathbb{E}_{t} \lambda_{t+1} q_{t+1}+\kappa_{t} q_{t} \pi_{t}\left(\varepsilon_{t}\right)
$$

If a household member with taste shock $\varepsilon_{t}$ purchases an additional unit of housing, the cost is $q_{t}$ units of goods and thus the utility cost is $q_{t} \eta\left(\varepsilon_{t}\right)$. The extra unit of housing yields utility gains from housing services of $\varphi \varepsilon_{t}\left[h_{t}\left(\varepsilon_{t}\right)\right]^{-\theta}$. The unit of housing can be sold at the price $q_{t+1}$ next period, with a present value of the utility gains of $\beta \mathbb{E}_{t} \lambda_{t+1} q_{t+1}$. In addition, having the extra unit of housing increases the collateral value and helps relax the collateral constraint, with the shadow utility value of $\kappa_{t} q_{t} \pi_{t}\left(\varepsilon_{t}\right)$. The optimal choice of $h_{t}\left(\varepsilon_{t}\right)$ equates the marginal cost to the sum of all marginal benefits.

The first-order condition with respect to $b_{t}\left(\varepsilon_{t}\right)$ is given by

$$
\eta_{t}\left(\varepsilon_{t}\right)=\beta R_{t} \mathbb{E}_{t} \lambda_{t+1}+\pi_{t}\left(\varepsilon_{t}\right)
$$

Borrowing an extra unit of goods has the utility value of $\eta_{t}\left(\varepsilon_{t}\right)$ for the member with taste shock $\varepsilon_{t}$. The family needs to repay the debt next period at the interest rate $R_{t}$, with the utility cost of $\beta R_{t} \mathbb{E}_{t} \lambda_{t+1}$. The increase in borrowing also tigtens the collateral constraint, with the utility cost of $\pi_{t}\left(\varepsilon_{t}\right)$. The optimal choice of $b_{t}\left(\varepsilon_{t}\right)$ equates the utility gains to the total costs.

III.2. Equilibrium. A competitive equilibrium is a collection of prices $\left\{q_{t}, R_{t}\right\}$ and allocations $\left\{c_{t}, a_{t}, h_{t}\left(\varepsilon_{t}\right), b_{t}\left(\varepsilon_{t}\right)\right\}$, such that

(1) Taking the prices as given, the allocations solve the household's utility maximizing problem.

(2) Markets for goods, housing, and credit all clear, so that

$$
\begin{aligned}
c_{t} & =y_{t} \\
\int h_{t}\left(\varepsilon_{t}\right) d F\left(\varepsilon_{t}\right) & =1 \\
\int b_{t}\left(\varepsilon_{t}\right) d F\left(\varepsilon_{t}\right) & =0,
\end{aligned}
$$

where we assume that the aggregate supply of housing is fixed at one and the aggregate net supply of debt is 0 . 
IV. Characterizing the equilibrium in the heterogeneous-AGent model

We now characterize the equilibrium. Intuitively, a household member with a higher $\varepsilon_{t}$ would like to purchase more housing. Since such purchases are partly financed by external debt, she will also face a binding borrowing constraint. We conjecture that there exists a cutoff level of the taste shock $\varepsilon_{t}^{*}$ such that $\pi_{t}\left(\varepsilon_{t}\right) \geq 0$ if $\varepsilon_{t} \geq \varepsilon_{t}^{*}$ and $\pi_{t}\left(\varepsilon_{t}\right)=0$ otherwise. The key step to find an equilibrium is to determine the cutoff $\varepsilon_{t}^{*}$.

Lemma IV.1 below gives the solution for the equilibrium housing purchase $h_{t}\left(\varepsilon_{t}\right)$ as well as the cutoff point $\varepsilon_{t}^{*}$.

Lemma IV.1. There exists a cutoff point $\varepsilon_{t}^{*}$ in the support of the distribution $F(\varepsilon)$, such that

$$
h_{t}\left(\varepsilon_{t}\right)=\min \left\{\left(\frac{\varepsilon_{t}}{\varepsilon_{t}^{*}}\right)^{\frac{1}{\theta}}, 1\right\} \frac{1}{1-\kappa_{t}} .
$$

The cutoff point $\varepsilon_{t}^{*}$ is determined by

$$
\int \min \left\{1,\left(\frac{\varepsilon}{\varepsilon_{t}^{*}}\right)^{\frac{1}{\theta}}\right\} f(\varepsilon) d \varepsilon=\left(1-\kappa_{t}\right) .
$$

Proof. For a household member with $\varepsilon_{t} \geq \varepsilon_{t}^{*}$, the borrowing constraint (20) is binding. Combining the flow-of-funds constraint (19) with the binding borrowing constraint, we obtain

$$
q_{t} h_{t}\left(\varepsilon_{t}\right)=a_{t}+\frac{b_{t}\left(\varepsilon_{t}\right)}{R_{t}}=a_{t}+\kappa_{t} q_{t} h_{t}\left(\varepsilon_{t}\right)
$$

Furthermore, by integrating the flow-of-funds constraint over $\varepsilon$ and imposing the market clearing conditions for housing and bond, we obtain

$$
a_{t}=q_{t} \int\left[h_{t}\left(\varepsilon_{t}\right)-\frac{b_{t}\left(\varepsilon_{t}\right)}{R_{t}}\right] d F\left(\varepsilon_{t}\right)=q_{t} .
$$

Thus, for $\varepsilon_{t} \geq \varepsilon_{t}^{*}$, Eq. (31) implies that

$$
h_{t}\left(\varepsilon_{t}\right)=\frac{a_{t}}{q_{t}\left(1-\kappa_{t}\right)}=\frac{1}{1-\kappa_{t}},
$$

which is independent of $\varepsilon_{t}$.

If $\varepsilon_{t}<\varepsilon_{t}^{*}$, then $\pi_{t}\left(\varepsilon_{t}\right)=0$. From Eq. (25), we have

$$
\eta_{t}\left(\varepsilon_{t}\right)=\beta R_{t} E_{t} \lambda_{t+1}=\eta_{t}\left(\varepsilon_{t}^{*}\right) \equiv \eta_{t}^{*}
$$

Furthermore, with $\pi_{t}\left(\varepsilon_{t}\right)=0$, Eq. (24) implies that

$$
\eta_{t}^{*} q_{t}=\varphi \varepsilon_{t}\left[h_{t}\left(\varepsilon_{t}\right)\right]^{-\theta}+\beta E_{t} \lambda_{t+1} q_{t+1},
$$


or

$$
\varphi \varepsilon_{t}\left[h_{t}\left(\varepsilon_{t}\right)\right]^{-\theta}=\varphi \varepsilon_{t}^{*}\left[h_{t}\left(\varepsilon_{t}^{*}\right)\right]^{-\theta}=\varphi \varepsilon_{t}^{*}\left(\frac{1}{1-\kappa_{t}}\right)^{-\theta} .
$$

Simple algebra yields that $h_{t}\left(\varepsilon_{t}\right)=\left(\frac{\varepsilon_{t}}{\varepsilon_{t}^{*}}\right)^{\frac{1}{\theta}} \frac{1}{1-\kappa_{t}}$ for $\varepsilon_{t}<\varepsilon_{t}^{*}$. This proves Eq. (29).

Integrating the solution (29) for $h_{t}\left(\varepsilon_{t}\right)$ over $\varepsilon_{t}$ and then imposing the housing market clearing condition (27), we obtain

$$
\int_{0}^{\varepsilon_{t}^{*}}\left(\frac{\varepsilon}{\varepsilon_{t}^{*}}\right)^{\frac{1}{\theta}} \frac{1}{1-\kappa_{t}} d F(\varepsilon)+\int_{\varepsilon_{t}^{*}}^{\infty} \frac{1}{1-\kappa_{t}} d F(\varepsilon)=1,
$$

Re-arranging term yields equation (30).

The threshold (or cutoff) point $\varepsilon_{t}^{*}$ is the solution to Equation (34). With some mild regularity assumptions on the distribution function $F(\varepsilon)$ and the upper bound of the loan-to-value ratio $\kappa_{t}$, we can show that $\varepsilon_{t}^{*}$ increases with $\kappa_{t}$. This result is formally stated in the following proposition.

Proposition IV.2. Assume that the support of the distribution of $\varepsilon$ lies in the interval $\left[0, \varepsilon_{\max }\right]$. Assume further that $\kappa_{t}$ is bounded above by $\kappa_{\max }$, where the upper bound is defined by $1-\kappa_{\max } \equiv \int_{0}^{\varepsilon_{\max }}\left(\frac{\varepsilon}{\varepsilon_{\max }}\right)^{\frac{1}{\theta}} f(\varepsilon) d \varepsilon$. Denote by $\varepsilon_{t}^{*} \equiv \varepsilon^{*}\left(\kappa_{t}\right)$ the solution of Eq. (30), such that $\varepsilon^{*}\left(\kappa_{t}\right) \in\left(0, \varepsilon_{\max }\right)$ for $\kappa_{t} \in\left(0, \kappa_{\max }\right)$. Then we have $\frac{\partial \varepsilon^{*}\left(\kappa_{t}\right)}{\partial \kappa_{t}}>0$.

Proof. For any $\tilde{\varepsilon} \in\left(0, \varepsilon_{\max }\right)$, we have

$$
\lim _{\tilde{\varepsilon} \rightarrow \varepsilon_{\max }} \int_{0}^{\varepsilon_{\max }} \min \left\{1,\left(\frac{\varepsilon}{\tilde{\varepsilon}}\right)^{\frac{1}{\theta}}\right\} f(\varepsilon) d \varepsilon=1-\kappa_{\max }<1-\kappa,
$$

where we have used the definition of $\kappa_{\max }$. We also have

$$
\lim _{\tilde{\varepsilon} \rightarrow 0} \int_{0}^{\varepsilon_{\max }} \min \left\{1,\left(\frac{\varepsilon}{\tilde{\varepsilon}}\right)^{\frac{1}{\theta}}\right\} f(\varepsilon) d \varepsilon=1>1-\kappa .
$$

By the Intermediate Value Theorem, Eq. (30) has an interior solution $\varepsilon_{t}^{*} \in\left(0, \varepsilon_{\max }\right)$. Since the left side of the equation strictly decreases with $\varepsilon_{t}^{*}$ and the right side strictly decreases with $\kappa_{t}$, it follows that $\frac{\partial \varepsilon^{*}\left(\kappa_{t}\right)}{\partial \kappa_{t}}>0$.

Proposition IV.2 shows that, if the loan-to-value ratio increases or equivalently, the downpayment ratio decreases, then there will be fewer credit-constrained house buyers. 
IV.1. Aggregate housing demand and price. The presence of credit-constrained buyers implies that the equilibrium housing price depends onxt both the average marginal utility across all individuals (i.e., the shadow rent) and a liquidity premium that stems from binding credit constraints. Specifically, integrating the individual housing Euler equations in (24) across $\varepsilon$, we obtain an expression for the housing price

$$
q_{t} \lambda_{t}=\mathbb{E}_{t} \beta \lambda_{t+1} q_{t+1}+\int_{0}^{\varepsilon_{\max }} \varphi \varepsilon\left[h_{t}\left(\varepsilon_{t}\right)\right]^{-\theta} d F(\varepsilon)+\int_{\varepsilon_{t}^{*}}^{\varepsilon_{\max }} \kappa_{t} q_{t} \pi_{t}\left(\varepsilon_{t}\right) d F(\varepsilon), \text { for } \theta>0
$$

where the first integral on the right side of the equation is just the average marginal utility or shadow rent, and the second integral is the liquidity premium, which is positive if and only if $\varepsilon>\varepsilon_{t}^{*}$. This result is formally stated in the following proposition.

Proposition IV.3. The equilibrium housing price satisfies the Euler equation

$$
q_{t} \lambda_{t}=\mathbb{E}_{t} \beta \lambda_{t+1} q_{t+1}+\xi\left(\kappa_{t}\right)
$$

where the term $\xi_{t} \equiv \xi\left(\kappa_{t}\right)$ is given by

$$
\xi\left(\kappa_{t}\right) \equiv \underbrace{\varphi\left(1-\kappa_{t}\right)^{\theta} \mathbb{E} \max \left\{\varepsilon, \varepsilon_{t}^{*}\right\}}_{\text {Average marginal utility }}+\underbrace{\frac{1}{1-\kappa_{t}} \int_{\varepsilon_{t}^{*}}^{\varepsilon_{\max }}\left(1-\kappa_{t}\right)^{\theta} \varphi\left(\varepsilon_{t}-\varepsilon_{t}^{*}\right) d F\left(\varepsilon_{t}\right)}_{\text {Liquidity premium } \Pi_{t}},
$$

Proof. We provide a proof in the Appendix.

Apparently, the Euler equation (36) in this heterogeneous-agent economy is isomorphic to the housing Euler equation (8) in the representative-agent economy. More formally, we have

Proposition IV.4. If $\xi\left(\kappa_{t}\right)=\varphi_{t}$, then the equilibrium housing price in the heterogeneousagent model coincides with that in the representative agent model.

Proof. From Proposition IV.3, the housing Euler equation in the heterogeneous-agent economy is given by

$$
\frac{q_{t}}{c_{t}}=\beta \mathbb{E}_{t} \frac{q_{t+1}}{c_{t+1}}+\xi\left(\kappa_{t}\right)
$$

The housing Euler equation in the representative-agent model is given by Eq. (3) and rewritten here for convenience of referencing:

$$
\frac{q_{t}}{c_{t}}=\beta \mathbb{E}_{t} \frac{q_{t+1}}{c_{t+1}}+\varphi_{t} h_{t}^{-\theta}
$$

In equilibrium, the housing market clears so that $h_{t}=1$. Thus, if $\xi\left(\kappa_{t}\right)=\varphi_{t}$, then the housing Euler equations in the two different economies are formally identical. 
Furthermore, goods market clearing implies that $c_{t}=y_{t}$ in both models. Thus, the equilibrium housing price is also identical.

Proposition IV.4 provides a microeconomic foundation for the reduced-form housing demand shock. In this specific example, aggregate housing demand is a function of the loan-to-value shocks $\kappa_{t}$ (as reflected in the $\xi\left(\kappa_{t}\right)$ function). In general, however, any shock that shifts the cutoff point $\varepsilon_{t}^{*}$ can shift the aggregate housing demand, and thus affect the housing price as well.

Eq. (37) shows that aggregate housing demand and the housing price depend on two terms: (i) the average marginal rate of substitution (MRS) between housing and nonhousing consumption across all agents (i.e., the implicit rent); and (ii) the liquidity premium stemming from binding collateral constraints for the subset of agents with high MRS. The liquidity premium drives a wedge between the house price and the implicit rent (corresponding to the average MRS), creating room for potentially large fluctuations in the price-to-rent ratio when the leverage conditions change.

IV.2. The marginal agent, credit supply, and the house price. The house price in our model always satisfies the Euler equation for the marginal agent, who faces the idiosyncratic shock $\varepsilon_{t}^{*}$. The marginal agent is not credit constrained and has the housing Euler equation

$$
q_{t} \frac{\eta_{t}^{*}}{\lambda_{t}}=\mathbb{E}_{t} \beta \frac{\lambda_{t+1}}{\lambda_{t}} q_{t+1}+M R S_{t}^{*}
$$

where $\eta_{t}^{*}=R_{t} \mathbb{E}_{t} \beta \frac{\lambda_{t+1}}{\lambda_{t}}$ is an increasing function of the risk-free interest rate $R_{t}$ and the term $M R S_{t}^{*}$ denotes the marginal agent's MRS between housing and non-housing consumption given by

$$
M R S_{t}^{*}=\frac{\varphi}{\lambda_{t}} \varepsilon_{t}^{*}\left(1-\kappa_{t}\right)^{\theta} .
$$

The Euler equation (40) shows that, for any given interest rate, the house price increases with $M R S_{t}^{*}$.

An increase in credit supply relaxes the credit constraints, and it has two opposing effects on the marginal agent's MRS. First, according to Proposition IV.2, an increase in $\kappa_{t}$ raises the cutoff point $\varepsilon_{t}^{*}$, and the new marginal agent has a higher MRS than in the original equilibrium (the extensive margin). All else equal, this extensive-margin effect raises the house price. However, a relaxation of credit constraints also enables the new marginal agent to enjoy more housing services, lowering her MRS through diminishing marginal utility (the intensive margin). All else equal, the intensivemargin effect reduces the house price. 
If the marginal agent has low risk aversion with respect to housing (i.e., $\theta<1$ ), then the extensive-margin effect (through shifting the cutoff point) dominates, and an increase in $\kappa_{t}$ raises the aggregate housing demand and the housing price. If the agent has high risk aversion $(\theta>1)$, then the intensive-margin effect (through diminishing marginal utility) dominates, and an increase in $\kappa_{t}$ reduces the housing demand and the house price. In the special case with $\theta=1$ (log-utility in housing), the two effects offset and the aggregate housing demand is invariant to credit availability.

These results are formally stated in the proposition below.

Proposition IV.5. Increases credit availability has a positive effect on aggregate housing demand and the housing price if and only if $\theta<1$. Specifically, if $\theta<1$, then $\frac{\partial \xi_{t}}{\partial \kappa_{t}}>0$ and $\frac{\partial q_{t}}{\partial \kappa_{t}}>0$; if $\theta \geq 1$, then $\frac{\partial \xi_{t}}{\partial \kappa_{t}} \leq 0$ and $\frac{\partial q_{t}}{\partial \kappa_{t}} \leq 0$.

Proof. We prove this proposition in the Appendix.

IV.3. Implicit rent and the price-to-rent ratio. To keep the model analytically tractable, we abstract from a rental housing market. If rental markets are frictionless, and in particular, if renting is not subject to borrowing constraints, then we can still use our model to shed light on the driving factors of fluctuations in implicit rents and the housing price-to-rent ratio. As we show in Section V.3, where we introduce an explicit rental market, the market rental rate equals the average MRS between housing and non-housing consumption across all agents. Accordingly, in our setup here without a formal rental market, it is natural to define an implicit rent as the average MRS across all agents. In particular, the implicit rent is given by

$$
r_{h t}=\frac{\varphi}{\lambda_{t}} \int_{0}^{\varepsilon_{\max }} \varepsilon_{t}\left[h_{t}\left(\varepsilon_{t}\right)\right]^{-\theta} d F\left(\varepsilon_{t}\right) .
$$

Since high-MRS agents face binding borrowing constraints, changes in credit availability (i.e., $\kappa_{t}$ ) have impact on the marginal utilities of those households, and thus changes in $\kappa_{t}$ should affect the average rent. The relation between the average rental rate and credit availability is ambiguous, as we formally state in the proposition below.

Proposition IV.6. For $\theta>0$, the average rent is given by

$$
r_{h t}=\frac{\varphi}{\lambda_{t}}\left(1-\kappa_{t}\right)^{\theta} \mathbb{E} \max \left\{\varepsilon, \varepsilon_{t}^{*}\right\} .
$$

The effect of changes in $\kappa_{t}$ on the average rent $r_{h t}$ is ambiguous.

Proof. The average rent in Eq. (43) corresponds to the first term in $\xi_{t}$ in Eq. (37), which we derive in the appendix. The term $\left(1-\kappa_{t}\right)^{\theta}$ decreases with $\kappa_{t}$, while the term 
$\mathbb{E} \max \left\{\varepsilon, \varepsilon_{t}^{*}\right\}$ increases with $\varepsilon_{t}^{*}$ and thus with $\kappa_{t}$ as well, since $\varepsilon_{t}^{*}$ itself increases with $\kappa_{t}$ according to Proposition IV.2. Thus, the effects of changes in $\kappa_{t}$ on $r_{h t}$ ambiguous.

In the special case with linear utility in housing (i.e., $\theta=0$ ), the average rent would be independent of $\kappa_{t}$. Specifically, with $\theta=0$, the implicit rent in Eq. (42) becomes

$$
r_{h t}=\frac{\varphi}{\lambda_{t}} \int_{0}^{\varepsilon_{\max }} \varepsilon\left[h_{t}(\varepsilon)\right]^{-\theta} d F(\varepsilon)=\varphi c_{t} \int_{0}^{\varepsilon_{\max }} \varepsilon d F(\varepsilon)=\varphi c_{t} .
$$

In contrast, the housing price increases with $\kappa_{t}$ when $\theta=0$, accordingly to Proposition IV.5. Thus, the price-to-rent ratio also increases with $\kappa_{t}$.

In the more general case with $\theta>0$, however, the relation between the price-to-rent ratio and $\kappa_{t}$ is non-linear, as we formally state in the proposition below.

Proposition IV.7. The steady-state housing price-to-rent ratio is given by

$$
\frac{q}{r_{h}}=\frac{1}{1-\beta} \frac{\mathbb{E} \max \left(\varepsilon, \varepsilon^{*}\right)+\frac{\kappa}{1-\kappa} \int_{\varepsilon_{t}^{*}}^{\infty}\left(\varepsilon_{t}-\varepsilon_{t}^{*}\right) d F\left(\varepsilon_{t}\right)}{\mathbb{E} \max \left(\varepsilon, \varepsilon^{*}\right)} .
$$

The price-to-rent ratio increases in $\kappa$ if $\kappa$ is sufficiently small, but it decreases with $\kappa$ if $\kappa$ is sufficiently large.

Proof. The housing Euler equation (36) implies that the steady-state housing price satisfies

$$
q=\frac{1}{1-\beta} \frac{1}{\lambda} \xi(\kappa)
$$

Using the definitions of $\xi(\kappa)$ in Eq. (37) and $r_{h}$ in Eq. (43), we obtain

$$
\begin{aligned}
\frac{q}{r_{h}} & =\frac{1}{1-\beta} \frac{(1-\kappa)^{\theta} \mathbb{E} \max \left(\varepsilon, \varepsilon^{*}\right)+\frac{\kappa}{1-\kappa} \int_{\varepsilon_{t}^{*}}^{\infty}\left(1-\kappa_{t}\right)^{\theta}\left(\varepsilon_{t}-\varepsilon_{t}^{*}\right) d F\left(\varepsilon_{t}\right)}{(1-\kappa)^{\theta} \mathbb{E} \max \left(\varepsilon, \varepsilon^{*}\right)} \\
& =\frac{1}{1-\beta} \frac{\mathbb{E} \max \left(\varepsilon, \varepsilon^{*}\right)+\frac{\kappa}{1-\kappa} \int_{\varepsilon_{t}^{*}}^{\infty}\left(\varepsilon_{t}-\varepsilon_{t}^{*}\right) d F\left(\varepsilon_{t}\right)}{\mathbb{E} \max \left(\varepsilon, \varepsilon^{*}\right)}
\end{aligned}
$$

If $\kappa=0$, then $\frac{q}{r_{h}}=\frac{1}{1-\beta}$. If $\kappa=\kappa_{\max }<1$, then $\varepsilon^{*}=\varepsilon_{\max }$, and we also have $\frac{q}{r_{h}}=\frac{1}{1-\beta}$. For $\kappa \in\left(0, \kappa_{\max }\right)$, we have $\varepsilon_{\min }<\varepsilon^{*}<\varepsilon_{\max }$

$$
\frac{q}{r_{h}}=\frac{1}{1-\beta}\left[1+\frac{\frac{\kappa}{1-\kappa} \int_{\varepsilon_{t}^{*}}^{\infty}\left(\varepsilon_{t}-\varepsilon_{t}^{*}\right) d F\left(\varepsilon_{t}\right)}{\mathbb{E} \max \left(\varepsilon, \varepsilon^{*}\right)}\right]>\frac{1}{1-\beta}
$$

The inequality follows from that fact that both term $\frac{\kappa}{1-\kappa}>0$ and $\int_{\varepsilon_{t}^{*}}^{\infty}\left(\varepsilon_{t}-\varepsilon_{t}^{*}\right) d F\left(\varepsilon_{t}\right)>$ 0 . Thus, there is an inverted U-shape relation between $\kappa$ and $\frac{q}{r_{h}}$. 
IV.4. A parametric example. To further understand the mechanism through which the housing price and the price-to-rent ratio are affected by credit market conditions, we consider a specific distribution of idiosyncratic shocks. Suppose that $\varepsilon$ follows a power distribution so that the cumulative density function is given by

$$
F(\varepsilon)=\left(\frac{\varepsilon}{\varepsilon_{\max }}\right)^{\eta}
$$

we assume $\varepsilon_{\max }=\frac{\eta+1}{\eta}$, so the mean $\mathbb{E} \varepsilon=\frac{\eta}{\eta+1} \varepsilon_{\max }=1$. We focus on the special case with $\eta=1$, so that $\varepsilon$ follows a uniform distribution. We also focus on the special case with $\theta=0$. Under these parameter restrictions, we are able to obtain simple closedform solutions for the housing price, the average implicit rent, and the price-to-rent ratio.

With $\theta=0$, Eq. (35) becomes

$$
q_{t} \lambda_{t}=\mathbb{E}_{t} \beta \lambda_{t+1} q_{t+1}+\int_{0}^{\varepsilon_{\max }} \varphi \varepsilon d F(\varepsilon)+\kappa_{t} \int_{\varepsilon_{t}^{*}}^{\varepsilon_{\max }} q_{t} \pi_{t}(\varepsilon) d F(\varepsilon)+\int_{0}^{\varepsilon_{\max }} \mu_{t}(\varepsilon) d F(\varepsilon) .
$$

It is easy to prove that $\mu_{t}(\varepsilon)=\varphi \max \left\{\varepsilon_{t}^{*}-\varepsilon, 0\right\}$ in the case with $\theta=0$ (see the appendix). The housing Euler equation (48) can be written in the compact form

$$
q_{t} \lambda_{t}=\mathbb{E}_{t} \beta \lambda_{t+1} q_{t+1}+\xi\left(\kappa_{t}\right)
$$

where the term $\xi\left(\kappa_{t}\right)$ is given by

$$
\xi\left(\kappa_{t}\right) \equiv \underbrace{\varphi \mathbb{E}(\varepsilon)}_{\text {Average marginal utility }}+\kappa_{t} \underbrace{\frac{1}{1-\kappa_{t}} \int_{\varepsilon_{t}^{*}}^{\varepsilon_{\max }} \varphi\left(\varepsilon_{t}-\varepsilon_{t}^{*}\right) d F\left(\varepsilon_{t}\right)}_{\text {Liquidity premium } \Pi_{t}}+\underbrace{\varphi \int_{0}^{\varepsilon_{t}^{*}}\left(\varepsilon_{t}^{*}-\varepsilon_{t}\right) d F\left(\varepsilon_{t}\right)}_{\text {Option value } \mathcal{O}_{t}}
$$

The first term is the average marginal utility across all agents. In the case with $\theta=0$, the implicit rent, which is the marginal rate substitution between housing and non-housing consumption, is independent of credit conditions, and is given by

$$
r_{h t}=\frac{\varphi}{\lambda_{t}} \int_{0}^{\varepsilon_{\max }} \varepsilon d F(\varepsilon)=\varphi c_{t}
$$

where we have imposed the assumption that the mean value of $\varepsilon$ is one.

The second term in the expression for $\xi\left(\kappa_{t}\right)$ is the liquidity premium (denoted by $\Pi_{t}$ ), the importance of which is weighed by the loan-to-value ratio $\kappa_{t}$. Imposing the distribution assumption for the idiosyncratic shocks, it is easy to show that the liquidity premium is given by

$$
\Pi_{t}=\varphi\left(1-\kappa_{t}\right) .
$$


Thus, the liquidity premium decreases with $\kappa_{t}$. A relaxation of credit constraints reduces the shadow value of internal funds, leading to a lower liquidity premium. However, a relaxation of credit constraints directly raises housing demand through increasing the borrowing capacity. The full impact is given by $\kappa \Pi\left(\kappa_{t}\right)=\varphi \kappa_{t}\left(1-\kappa_{t}\right)$. The increase in borrowing capacity counteracts the decrease in liquidity premium, and the net effect is concave in $\kappa_{t}$, reaching its maximum at $\kappa=0.5$.

The third term in the expression for $\xi\left(\kappa_{t}\right)$ is the option value (denoted by $\mathcal{O}_{t}$ ), which can be reduced to

$$
\mathcal{O}_{t}=\varphi \kappa_{t}^{2}
$$

Adding up all components, we obtain the following closed form solution for $\xi\left(\kappa_{t}\right)$

$$
\xi\left(\kappa_{t}\right)=\varphi+\varphi \kappa_{t}\left(1-\kappa_{t}\right)+\varphi \kappa_{t}^{2}=\varphi\left(1+\kappa_{t}\right) .
$$

In this example, aggregate housing demand (captured by $\xi\left(\kappa_{t}\right)$ ) increases with $\kappa_{t}$, so that the house price also increases with $\kappa_{t}$. However, the implicit rent $\left(r_{h t}\right)$ derived from the average marginal utility across all agents is independent of $\kappa_{t}$, as shown in Eq. (51). Thus, the model here is capable of generating much larger fluctuations in the house price than in the implicit rent, and the implied price-to-rent ratio is as volatile as the house price and the two variables strongly comove (they are in fact perfectly correlated).

This result obtained in our heterogeneous-agent model stands in contrast to that from the representative-agent model, which fails to generate the observed large fluctuations in the price-to-rent ratio. In this sense, our model provides a potential explanation of the price-to-rent puzzle.

IV.5. Evidence for model's mechanism. The theoretical model implies that a credit supply shock can have a large impact on the house price, but not on rent. We now present some empirical evidence that supports this model implication.

We identify a credit supply shock using the methodology of Mian et al. (2017). Specifically, we use the data from 25 advanced economies to identify a credit supply shock as the changes in the household debt-to-GDP ratio predicted by low mortgage interest rate spreads. The mortgage interest rate spread is the difference between the mortgage interest rates and the 10-year sovereign bond yields. The sample ranges from 1965 to 2013, with different starting years for different countries. We present some summary statistics of the data in the Appendix (Table A1).

To examine the dynamic responses of the house price and the rent to a credit supply shock, we use the local projection method of Jorda (2005) to estimate the cumulative 
responses of the variable of interest (house price or rent) in period $t+h$ relative to period $t$ following an identified credit supply shock in period $t$ and up to 10 periods before, for each projection horizon $h$. Given each $h \in\{0,1, \ldots, 10\}$, we run a two-stage local projection regression based on the empirical specification

$$
\log Y_{i, t+h}-\log Y_{i t}=\alpha_{0}^{h}+\sum_{j=0}^{10} \beta_{j}^{h} \Delta D_{i, t-j}^{H H}+\gamma_{i}^{h}+u_{i, t+h}^{h}
$$

where $Y_{i, t+h}$ denotes the house price (or rent) in country $i$ and period $t+h, \Delta D_{i t}^{H H}$ denotes the year-over-year log-changes in the household debt-to-GDP ratio in country $i$ and year $t, u_{i, t+h}^{h}$ is a regression residual, the parameters $\alpha_{0}^{h}$ and $\beta_{j}^{h}$ are common for all countries, and the parameter $\gamma_{i}^{h}$ captures the country fixed effects. We instrument the log-growth rates of the household debt-to-GDP ratio by a dummy variable that equals one if the mortgage interest rate spread is below the median and zero otherwise. The first-stage regression results are shown in the Appendix (Table A2).

Figure 3 shows that a credit supply expansion leads to a large and statistically significant increase in the house price. A one-percent increase in the annual growth rate of the household debt-to-GDP ratio associated with a low mortgage spread leads to a 7.5 percent increase in the house price at the peak, and the effects remain significant for about 6 years. This finding is consistent with the literature (Mian et al., 2017; Jordà et al., 2016). In contrast, the responses of the rent to a credit supply shock is small and statistically insignificant, as shown in Figure 4. These empirical findings lend support to our theory that credit supply shocks can drive large fluctuations in both the house price and the price-to-rent ratio.

\section{Robustness}

In this section, we show that the main results obtain in our benchmark heterogeneousagent model are robust to an alternative source of heterogeneity or shocks and also to the presence of an explicit rental market.

V.1. Heterogeneity in income. The main insights from our benchmark heterogeneousagent model do not hinge upon the particular way of modeling heterogeneity. We now consider a different type of heterogeneity. Instead of assuming idiosyncratic preference shocks, we consider idiosyncratic income shocks. We show that all the main results obtained above carry over to this alternative setup.

Consider a household family with a continuum of members. All members enjoy the same consumption $c_{t}$. Each member gets a transfer payment $a_{t}$ from the family 
for purchasing houses in the decentralized housing market. Before their house purchase decisions, they each receives an idiosyncratic shock $\omega_{t}$ so that their effective net worth is $\omega_{t} a_{t}$. Since households with different realizations of $\omega_{t}$ make different house purchasing decisions, the housing services in the utility function for each member are indexed by $\omega_{t}$. The household utility function is given by

$$
\mathbb{E}_{0} \sum_{t=0}^{\infty} \beta^{t}\left[\log c_{t}+\varphi \int_{0}^{\infty} \frac{\left[h_{t}\left(\omega_{t}\right)\right]^{1-\theta}}{1-\theta} d F\left(\omega_{t}\right)\right]
$$

where $h_{t}\left(\omega_{t}\right)$ denotes housing held by the household member with the shock $\omega_{t}$, drawn from the distribution $F(\omega)$. All the other variables and parameters have the same interpretations as in the benchmark model.

The family faces the budget constraint

$$
c_{t}+a_{t}=y_{t}+q_{t} \int h_{t-1}\left(\omega_{t-1}\right) d F\left(\omega_{t-1}\right)-\int b_{t-1}\left(\omega_{t-1}\right) d F\left(\omega_{t-1}\right),
$$

where $b_{t-1}\left(\omega_{t-1}\right)$ denotes previous-period debt of the family member who had idiosyncratic income shock $\omega_{t-1}$.

In the decentralized housing markets, the household member with shock $\omega_{t}$ finances house purchases with both internal funds $\omega_{t} a_{t}$ and external debt $b\left(\omega_{t}\right)$, subject to the flow-of-funds constraint

$$
q_{t} h_{t}\left(\omega_{t}\right) \leq \omega_{t} a_{t}+\frac{b_{t}\left(\omega_{t}\right)}{R_{t}}
$$

and the borrowing constraint

$$
\frac{b_{t}\left(\omega_{t}\right)}{R_{t}} \leq \kappa_{t} q_{t} h_{t}\left(\omega_{t}\right)
$$

where, as in the benchmark model, the risk-free interest rate $R_{t}$ and the loan-to-value ratio $\kappa_{t}$ are common for all borrowers.

Denote by $\lambda_{t}, \eta_{t}\left(\omega_{t}\right)$, and $\pi_{t}\left(\omega_{t}\right)$ the Lagrangian multiplers associated with the constraints (57), (58), and (59), respectively. The first order condition with respect to $c_{t}$ is given by

$$
\frac{1}{c_{t}}=\lambda_{t}
$$

The first order condition with respect to $a_{t}$ implies

$$
\lambda_{t}=\int \eta_{t}\left(\omega_{t}\right) d F\left(\omega_{t}\right)
$$

The first order condition with respect to $h_{t}\left(\omega_{t}\right)$ is given by

$$
\eta_{t}\left(\omega_{t}\right) q_{t}=\varphi\left[h_{t}(\omega)\right]^{-\theta}+\beta \mathbb{E}_{t} \lambda_{t+1} q_{t+1}+\kappa_{t} q_{t} \pi_{t}\left(\omega_{t}\right)
$$


The first order condition with respect to $b_{t}\left(\omega_{t}\right)$ is

$$
\frac{1}{R_{t}} \eta_{t}\left(\omega_{t}\right)=\beta E_{t} \lambda_{t+1}+\frac{1}{R_{t}} \pi_{t}\left(\omega_{t}\right)
$$

These optimizing conditions have similar interpretations as in the benchmark model. We can define an equilibrium analogous to that in the benchmark model with heterogeneous preferences..

We show in Appendix D that there exists a unique cutoff point $\omega_{t}^{*}$ in the support of the distribution $F(\omega)$ such that individual housing demand is given by

$$
h_{t}\left(\omega_{t}\right)= \begin{cases}\frac{\omega_{t}^{*}}{1-\kappa_{t}} & \text { if } \omega_{t} \geq \omega_{t}^{*} \\ \frac{\omega_{t}}{1-\kappa_{t}} & \text { if } \omega_{t}<\omega_{t}^{*}\end{cases}
$$

The cutoff point $\omega_{t}^{*}$ is an implicit function of the loan-to-value ratio $\kappa_{t}$, and is solved from the house market clearing condition

$$
\frac{1}{1-\kappa_{t}} \int_{\omega_{\min }}^{\omega_{t}^{*}} \omega f(\omega) d \omega+\left(1-F\left(\omega_{t}^{*}\right)\right) \frac{\omega_{t}^{*}}{1-\kappa_{t}}=1 .
$$

Aggregating the housing Euler equations across individuals and using the individual housing demand in Eq (64), we obtain the aggregate housing Euler equation

$$
\lambda_{t} q_{t}=\mathbb{E}_{t} \beta \lambda_{t+1} q_{t+1}+\zeta\left(\kappa_{t}\right)
$$

where

$$
\zeta\left(\kappa_{t}\right) \equiv \varphi\left[\frac{\omega_{t}^{*}}{1-\kappa_{t}}\right]^{-\theta}+\varphi\left(1-\kappa_{t}\right)^{\theta-1} \int_{\omega_{\min }}^{\omega_{t}^{*}}\left(\omega^{-\theta}-\omega_{t}^{*-\theta}\right) f(\omega) d \omega .
$$

In the expression for $\zeta\left(\kappa_{t}\right)$, the first term is the average marginal utility across all home buyers and the second term is the liquidity premium, which is positive if and only if $\omega<\omega_{t}^{*}$.

The aggregated housing Euler equation (66) provides a mapping between our model here with heterogeneous incomes and the representative-agent economy. In particular, if $\zeta\left(\kappa_{t}\right)=\varphi_{t}$, then the equilibrium house price in this heterogeneous-agent model coincides with that in the representative agent model. Thus, this model with heterogeneous income also provides a microeconomic foundation for aggregate housing demand shocks.

Similar to the benchmark heterogeneous-agent economy, changes in credit conditions represented by changed in $\kappa_{t}$ can drive changes in aggregate housing demand and thus the house price as well. This is because the house price needs to satisfy the marginal agent's housing Euler equation

$$
q_{t} \frac{\eta_{t}\left(\omega_{t}^{*}\right)}{\lambda_{t}}=\mathbb{E}_{t} \beta \frac{\lambda_{t+1}}{\lambda_{t}} q_{t+1}+M R S_{t}\left(\omega_{t}^{*}\right)
$$


where $\eta_{t}\left(\omega_{t}^{*}\right)=R_{t} \mathbb{E}_{t} \beta \frac{\lambda_{t+1}}{\lambda_{t}}$ increases with the risk-free interest rate $R_{t}$ and the term $M R S_{t}\left(\omega_{t}^{*}\right)$ denotes the marginal agent's marginal rate of substitution between housing and non-housing consumption. For any given interest rate, the house price increases with the marginal agent's MRS, which is given by

$$
M R S_{t}\left(\omega_{t}^{*}\right)=\frac{\varphi}{\lambda_{t}}\left(\omega_{t}^{*}\right)^{-\theta}\left(1-\kappa_{t}\right)^{\theta}
$$

Eq. (65) implies that $\omega^{*}$ itself decreases with $\kappa$. In particular,

$$
\frac{\partial \omega_{t}^{*}}{\partial \kappa_{t}}=-\frac{1}{1-F\left(\omega_{t}^{*}\right)}<0
$$

Thus, for any given interest rate $R$, the house price increases with credit supply measured by $\kappa$.

V.2. Uncertainty shocks. Aggregate housing demand and the house price are driven by not just shocks to credit conditions, but also by fluctuations in the distribution function of the idiosyncratic risks. We now discuss how idiosyncratic uncertainty shocks can shift aggregate housing demand.

The true idiosyncratic shock is $\varepsilon_{t}$, which has the distribution function $F(\varepsilon)$. However, the household members receive a noise signal about $\varepsilon$ in the beginning of each period, and that signal is informative about $\varepsilon$ with probability $p_{t}$, and uninformative with probability $1-p_{t}$. If the signal is uninformative, then the member learns nothing about the realized value of $\varepsilon$ from observing the signal $s_{t}$, and the conditional expectation of $\varepsilon$ is the same as the population mean of $\varepsilon$ (which is normalized to one). A smaller value of $p_{t}$ means a noisier signal and thus higher uncertainty.

Given this type of idiosyncratic uncertainty, the expected utility function of the household family is given by

$$
\begin{aligned}
& \mathbb{E}_{0} \sum_{t=0}^{\infty} \beta^{t}\left[\log c_{t}+\varphi \int_{0}^{\infty} \frac{\mathbb{E}\left[\varepsilon_{t}\left[h_{t}\left(s_{t}\right)\right]^{1-\theta} \mid s_{t}\right]}{1-\theta} d F\left(s_{t}\right)\right] \\
= & \mathbb{E}_{0} \sum_{t=0}^{\infty} \beta^{t}\left[\log c_{t}+\varphi \int_{0}^{\infty} \frac{\left(1-p_{t}+p_{t} s_{t}\right)\left[h_{t}\left(s_{t}\right)\right]^{1-\theta}}{1-\theta} d F\left(s_{t}\right)\right] .
\end{aligned}
$$

As in the benchmark model, the household family faces the budget constraint

$$
c_{t}+a_{t}=y_{t}+q_{t} \int h_{t-1}\left(s_{t-1}\right) d F\left(s_{t-1}\right)-\int b_{t-1}\left(s_{t-1}\right) d F\left(s_{t-1}\right) .
$$

In the decentralized housing markets, a member who observes the signal $s_{t}$ finances his spending on new housing $q_{t} h_{t}\left(s_{t}\right)$ using both internal funds $a_{t}$ received from the 
family and external borrowing of $b_{t}\left(s_{t}\right)$ at the interest rate $R_{t}$. The flow-of-funds constraint for the household member $s_{t}$ is given by

$$
q_{t} h_{t}\left(s_{t}\right) \leq a_{t}+\frac{b_{t}\left(s_{t}\right)}{R_{t}}
$$

A home buyer faces the collateral constraint

$$
\frac{b_{t}\left(s_{t}\right)}{R_{t}} \leq \kappa_{t} q_{t} h_{t}\left(s_{t}\right)
$$

where the loan-to-value ratio $\kappa_{t} \in[0,1]$ is exogenous and potentially time varying, representing shocks to credit conditions. Home purchases are also subject to the non-shortselling constraint

$$
h_{t}\left(s_{t}\right) \geq 0
$$

Following the derivations in the benchmark model, we show in the appendix that there exists a cutoff point $s_{t}^{*}$ such that household members face binding collateral constraints if and only if observed signal $s_{t}>s_{t}^{*}$. The housing price $q_{t}$ satisfies the aggregate housing Euler equation

$$
q_{t} \lambda_{t}=\mathbb{E}_{t} \beta \lambda_{t+1} q_{t+1}+\xi\left(\kappa_{t}, p_{t}\right)
$$

where the function $\xi_{t} \equiv \xi\left(\kappa_{t}, p_{t}\right)$ is given by

$$
\xi\left(\kappa_{t}, p_{t}\right) \equiv \underbrace{\varphi\left(1-\kappa_{t}\right)^{\theta}\left[\left(1-p_{t}\right)+p_{t} \mathbb{E} \max \left\{s, s_{t}^{*}\right\}\right]}_{\text {Average marginal utility }}+\underbrace{\frac{\kappa_{t}}{1-\kappa_{t}} p_{t} \int_{s_{t}^{*}}^{\varepsilon_{\max }}\left(1-\kappa_{t}\right)^{\theta} \varphi\left(s_{t}-s_{t}^{*}\right) d F\left(\varepsilon_{t}\right)}_{\text {liquidity premium }} .
$$

Thus, aggregate housing demand captured by the function $\xi\left(\kappa_{t}, p_{t}\right)$ depends on both the credit condition shock $\left(\kappa_{t}\right)$ and the idiosyncratic uncertainty shock $\left(p_{t}\right)$.

The housing market clearing condition is given by

$$
\int_{0}^{s_{t}^{*}}\left(\frac{1-p_{t}+p_{t} s}{1-p_{t}+p_{t} s_{t}^{*}}\right)^{\frac{1}{\theta}} \frac{1}{1-\kappa_{t}} d F(\varepsilon)+\int_{s_{t}^{*}}^{\varepsilon_{\max }} \frac{1}{1-\kappa_{t}} d F(\varepsilon)=1 .
$$

We can see more clearly how the equilibrium house price depends on the uncertainty shock $p_{t}$ in the special case with $\theta=0$. In this case, the housing market clearing condition (77) becomes

$$
\int_{s_{t}^{*}}^{\varepsilon_{\max }} \frac{1}{1-\kappa_{t}} d F(\varepsilon)=1
$$

Thus, the cutoff point $s_{t}^{*}$ is a function of $\kappa_{t}$ only, and is independent of the uncertainty shock $p_{t}$. 
With $\theta=0$, the function $\xi\left(\kappa_{t}, p_{t}\right)$ reduces to

$$
\xi\left(\kappa_{t}, p_{t}\right) \equiv \underbrace{\varphi}_{\text {Average }}+\underbrace{\frac{\kappa_{t}}{1-\kappa_{t}} p_{t} \int_{s_{t}^{*}}^{\varepsilon_{\max }} \varphi\left(s_{t}-s_{t}^{*}\right) d F\left(s_{t}\right)}_{\text {marginal utility }}+\underbrace{p_{t} \int_{0}^{s_{t}^{*}}\left(s_{t}^{*}-s_{t}\right) d F\left(s_{t}\right)}_{\text {Option value }} .
$$

Since $s_{t}^{*}$ is independent of $p_{t}$, it is straightforward to show that

$$
\frac{\partial \xi\left(\kappa_{t}, p_{t}\right)}{\partial p_{t}} \equiv \frac{\kappa_{t}}{1-\kappa_{t}} \int_{s_{t}^{*}}^{\varepsilon_{\max }}\left(1-\kappa_{t}\right)^{\theta} \varphi\left(s_{t}-s_{t}^{*}\right) d F\left(s_{t}\right)+\int_{0}^{s_{t}^{*}}\left(s_{t}^{*}-s_{t}\right) d F\left(s_{t}\right)>0
$$

Thus, while the average marginal utility (or the implicit rent) is a constant $\varphi$, the aggregate housing demand shock increases with $p_{t}$. Therefore, a reduction in uncertainty (i.e., and increase in $p_{t}$ ) raises housing demand and the equilibrium house price. It also raises the price-to-rent ratio.

V.3. Rental Market. We now introduce an explicit rental market for housing into our model. We show that, in this environment with a frictionless rental market, the market rental rate for housing corresponds to the average MRS across all agents, as does the implicit rent in the benchmark model (see Eq. (42)). The incorporation of a frictionless rental market represents a minimal departure from our benchmark model.

Consider a model economy in which the household enjoys utility from consumption of non-housing goods $c_{t}$ and housing services. Housing services are derived from either rental units or owner-occupied units. The household family can perfectly insure risks in goods consumption and rental services, so that those markets are frictionless. However, owner-occupied housing markets have frictions; and in particular, members with different taste shocks trade owner-occupied housing units in a decentralized market subject to collateral constraints. We implement this model structure by adopting a particular timing of decisions. In the beginning of each period $t$, the household family chooses goods consumption $c_{t}$ and rental services $\ell_{t}$, as well as some internal funds $a_{t}$ to be allocated to individual members in the decentralized owner-occupied housing market. After these decisions, an idiosyncratic taste shock $\varepsilon$ drawn from the distribution $F(\varepsilon)$ is realized, and household members go out to the decentralized housing market to purchase additional housing units. Such purchases can be financed by either internal funds or external debt (or both). The borrowing capacity of an individual member with taste shock $\varepsilon$ is limited by a fraction $\kappa_{t}$ of the value of the housing unit $h(\varepsilon)$. 
The household has the expected utility function

$$
\mathbb{E}_{0} \sum_{t=0}^{\infty} \beta^{t}\left[\log c_{t}+\varphi \int_{0}^{\infty} \frac{\varepsilon_{t}\left[\ell_{t}+h_{t}\left(\varepsilon_{t}\right)\right]^{1-\theta}}{1-\theta} d F\left(\varepsilon_{t}\right)\right],
$$

where $\ell_{t}$ denotes the rental housing services, and the other notations are identical to those in the benchmark model. The decisions for both goods consumption and rental services consumption are made in the beginning of the period, before the realization of the idiosyncratic shock $\varepsilon_{t}$. Once the idiosyncratic shock is realized, the household is split into a continuum of members, each indexed with the realized taste shock $\varepsilon_{t}$, and they all go out to a decentralized housing market to purchase owner-occupied units $h\left(\varepsilon_{t}\right)$. We assume that the household is endowed with a fixed amount of rental housing units $\ell$. The household faces the budget constraint

$$
c_{t}+a_{t}+r_{h t} \ell_{t}=y_{t}+q_{t} \int h_{t-1}\left(\varepsilon_{t-1}\right) d F\left(\varepsilon_{t-1}\right)-\int b_{t-1}\left(\varepsilon_{t-1}\right) d F\left(\varepsilon_{t-1}\right)+r_{h t} \ell .
$$

In the decentralized housing markets, a member with idiosyncratic shock $\varepsilon_{t}$ finances his spending on new housing $q_{t} h_{t}\left(\varepsilon_{t}\right)$ using both internal funds $a_{t}$ received from the household family and external borrowing $b_{t}\left(\varepsilon_{t}\right)$ at the interest rate $R_{t}$. The flow-offunds constraint for the member indexed by $\varepsilon_{t}$ is given by

$$
q_{t} h_{t}\left(\varepsilon_{t}\right) \leq a_{t}+\frac{b_{t}\left(\varepsilon_{t}\right)}{R_{t}}
$$

The borrowing capacity of the member with $\varepsilon_{t}$ is subject to the collateral constraint

$$
\frac{b_{t}\left(\varepsilon_{t}\right)}{R_{t}} \leq \kappa_{t} q_{t} h_{t}\left(\varepsilon_{t}\right)
$$

where the loan-to-value ratio $\kappa_{t} \in[0,1]$ represent exogenous shocks to credit conditions. We further impose the short-sale restriction on owner-occupied units, such that

$$
h_{t}\left(\varepsilon_{t}\right) \geq 0, \forall \varepsilon_{t} \sim F(\varepsilon) .
$$

Denote by $\lambda_{t}, \eta_{t}\left(\varepsilon_{t}\right), \pi_{t}\left(\varepsilon_{t}\right)$ and $\mu_{t}\left(\varepsilon_{t}\right)$ the Lagrangian multipliers associated with Equations (82)-(85), respectively. Then the first order condition with respect to $c_{t}$ is given by

$$
\frac{1}{c_{t}}=\lambda_{t}
$$

The first order condition with respect to $a_{t}$ implies

$$
\lambda_{t}=\int \eta_{t}\left(\varepsilon_{t}\right) d F\left(\varepsilon_{t}\right)
$$

A marginal unit of goods transferred to individual members for housing purchases reduces family consumption by one unit and hence the utility cost is $\lambda_{t}$. The utility 
gain from this transfer is the shadow value of newly purchased housing (i.e., $\eta_{t}\left(\varepsilon_{t}\right)$ ) averaged across all members.

The first order condition with respect to $\ell_{t}$ implies

$$
r_{h t}=\frac{1}{\lambda_{t}} \varphi \int_{0}^{\infty} \varepsilon_{t}\left[\ell_{t}+h_{t}\left(\varepsilon_{t}\right)\right]^{-\theta} d F\left(\varepsilon_{t}\right)
$$

Thus, the market rental price equals the average MRS between housing and nonhousing consumption across all members of the household.

The first order condition with respect to $h_{t}\left(\varepsilon_{t}\right)$ yields

$$
\eta_{t}\left(\varepsilon_{t}\right) q_{t}=\varphi \varepsilon_{t}\left[\ell_{t}+h_{t}\left(\varepsilon_{t}\right)\right]^{-\theta}+\beta \mathbb{E}_{t} \lambda_{t+1} q_{t+1}+\kappa_{t} q_{t} \pi_{t}\left(\varepsilon_{t}\right)+\mu_{t}\left(\varepsilon_{t}\right)
$$

The first-order condition with respect to $b_{t}\left(\varepsilon_{t}\right)$ is given by

$$
\eta_{t}\left(\varepsilon_{t}\right)=\beta R_{t} \mathbb{E}_{t} \lambda_{t+1}+\pi_{t}\left(\varepsilon_{t}\right) .
$$

The solution to this problems can be characterized by two cutoffs. Intuitively, a member with a sufficiently high marginal utility of housing (i.e., high $\varepsilon_{t}$ ) wants to purchase as much owner-occupied housing units as allowed by the borrowing constraint, whereas a member with a sufficiently low marginal utility would not want to buy new owner-occupied units at all. The solution to the owner-occupied housing is formally described by the following proposition.

Proposition V.1. There exists a cutoff point $\varepsilon_{t}^{*}$ in the support of the distribution $F(\varepsilon)$, such that

$$
h_{t}\left(\varepsilon_{t}\right)=\left\{\begin{array}{cc}
\frac{1}{1-\kappa_{t}} & \text { if } \varepsilon_{t} \geq \varepsilon_{t}^{*}, \\
\max \left\{\left(\frac{\varepsilon_{t}}{\varepsilon_{t}^{*}}\right)^{\frac{1}{\theta}}\left(\ell_{t}+\frac{1}{1-\kappa_{t}}\right)-\ell_{t}, 0\right\} & \text { otherwise }
\end{array}\right.
$$

In equilibrium $\ell_{t}=\ell$. Define $\varepsilon_{\ell t}^{*}$ as

$$
\varepsilon_{\ell t}^{*}=\left(\frac{\ell_{t}}{\ell_{t}+\frac{1}{1-\kappa_{t}}}\right)^{\theta} \varepsilon_{t}^{*}
$$

The cutoff point $\varepsilon_{t}^{*}$ is determined by

$$
\int_{\varepsilon_{\ell t}^{*}}^{\varepsilon_{t}^{*}}\left[\left(\frac{\varepsilon_{t}}{\varepsilon_{t}^{*}}\right)^{\frac{1}{\theta}}\left(\ell_{t}+\frac{1}{1-\kappa_{t}}\right)-\ell_{t}\right] f(\varepsilon) d \varepsilon+\int_{\varepsilon_{t}^{*}}^{\varepsilon_{\max }} \frac{1}{1-\kappa_{t}} f(\varepsilon) d \varepsilon=1
$$

Proof. For a household member with $\varepsilon_{t} \geq \varepsilon_{t}^{*}$, the borrowing constraint is binding and hence the flow of funds constraint yields

$$
h_{t}\left(\varepsilon_{t}\right)=\frac{a_{t}}{q_{t}\left(1-\kappa_{t}\right)}=\frac{1}{1-\kappa_{t}}
$$

which is independent of $\varepsilon_{t}$. 
If $\varepsilon_{t}<\varepsilon_{t}^{*}$, then $\pi_{t}\left(\varepsilon_{t}\right)=0$. We have

$$
\eta_{t}\left(\varepsilon_{t}\right)=\beta R_{t} E_{t} \lambda_{t+1}=\eta_{t}\left(\varepsilon_{t}^{*}\right) \equiv \eta_{t}^{*}
$$

Furthermore, with $\pi_{t}\left(\varepsilon_{t}\right)=0$, Eq. (24) implies that

$$
\eta_{t}^{*} q_{t}=\varphi \varepsilon_{t}\left[\ell_{t}+h_{t}\left(\varepsilon_{t}\right)\right]^{-\theta}+\beta E_{t} \lambda_{t+1} q_{t+1}+\mu_{t}\left(\varepsilon_{t}\right),
$$

if $\mu_{t}\left(\varepsilon_{t}\right)=0$, then we must have

$$
\varphi \varepsilon_{t}\left[\ell_{t}+h_{t}\left(\varepsilon_{t}\right)\right]^{-\theta}=\varphi \varepsilon_{t}^{*}\left[\ell_{t}+h_{t}\left(\varepsilon_{t}^{*}\right)\right]^{-\theta}=\varphi \varepsilon_{t}^{*}\left(\ell_{t}+\frac{1}{1-\kappa_{t}}\right)^{-\theta} .
$$

Simple algebra yields that $h_{t}\left(\varepsilon_{t}\right)=\left(\frac{\varepsilon_{t}}{\varepsilon_{t}^{*}}\right)^{\frac{1}{\theta}}\left(\ell_{t}+\frac{1}{1-\kappa_{t}}\right)-\ell_{t}$. By the definition of $\varepsilon_{\ell t}^{*}$ we have $h_{t}\left(\varepsilon_{t}\right) \geq 0$ if $\varepsilon_{t} \geq \varepsilon_{\ell t}^{*}$. Finally, if $\varepsilon_{t}<\varepsilon_{\ell t}^{*}, h_{t}\left(\varepsilon_{t}\right)=0$. The housing market clearing condition then implies

$$
\int_{\varepsilon_{\ell t}^{*}}^{\varepsilon_{t}^{*}}\left[\left(\frac{\varepsilon_{t}}{\varepsilon_{t}^{*}}\right)^{\frac{1}{\theta}}\left(\ell_{t}+\frac{1}{1-\kappa_{t}}\right)-\ell_{t}\right] f(\varepsilon) d \varepsilon+\int_{\varepsilon_{t}^{*}}^{\varepsilon_{\max }} \frac{1}{1-\kappa_{t}} f(\varepsilon) d \varepsilon=1 .
$$

We now consider how aggregate housing demand and thus the house price are determined in equilibrium. For simplicity, we focus on the special case with $\theta=0$ and relegate the presentation of the general case to the Appendix ???. The following proposition summarizes the main result.

Proposition V.2. In the special case with $\theta=0$, the aggregate housing Euler equation is given by

$$
q_{t} \lambda_{t}=\beta \mathbb{E}_{t} \lambda_{t+1} q_{t+1}+\xi_{t}
$$

where the term $\xi_{t}$ is given by

$$
\xi_{t}=\varphi\left[1+\frac{\kappa_{t}}{1-\kappa_{t}} \int_{\varepsilon_{t}^{*}}^{\varepsilon_{\max }}\left(\varepsilon_{t}-\varepsilon_{t}^{*}\right) f(\varepsilon) d \varepsilon+\int_{0}^{\varepsilon_{t}^{*}}\left(\varepsilon_{t}^{*}-\varepsilon_{t}\right) f(\varepsilon) d \varepsilon\right],
$$

which is increasing in credit availability $\kappa_{t}$. The market rent is given by

$$
r_{h t}=\frac{\varphi}{\lambda_{t}}
$$

which is independent of $\kappa_{t}$.

Proof. We provide a proof in the appendix. 
It follows that the equilibrium house price in this heterogeneous-agent model with a rental market is identical to that in the benchmark model, and both coincides with the house price in the representative-agent economy if $\xi_{t}=\varphi_{t}$. Furthermore, since the house price increases with credit availability $\kappa_{t}$, whereas the market rent is independent of $\kappa_{t}$, the price-to-rent ratio increases with $\kappa_{t}$.

Thus, in this model with an explicit rental market, we obtain qualitatively similar results as those in the benchmark model.

\section{CONClusion}

The standard macro models of housing have difficulties in generating the observed large fluctuations of both the house price and the price-to-rent ratio, because those models rely on reduced-form housing demand shocks that impact on both the price and the rent. We propose a microeconomic foundation for housing demand shocks based on a heterogeneous-agent model with idiosyncratic shocks and credit constraints. Since agents with different idiosyncratic shocks have different marginal utilities of housing, a subset of high-marginal utility agents face binding credit constraints, giving rise to an endogenous liquidity premium. The liquidity premium drives a wedge between the house price and the implicit rent, allowing credit supply expansion to generate large increases in both the house price and the price-to-rent ratio. Our model's main prediction that a credit supply shock has a large impact on the house price but not on the rent is supported by cross-country evidence.

Understanding the microeconomic forces that underpin aggregate housing demand and house prices is an important first step for designing appropriate policy interventions in the housing market. We hope that our work contributes to this promising research area. 


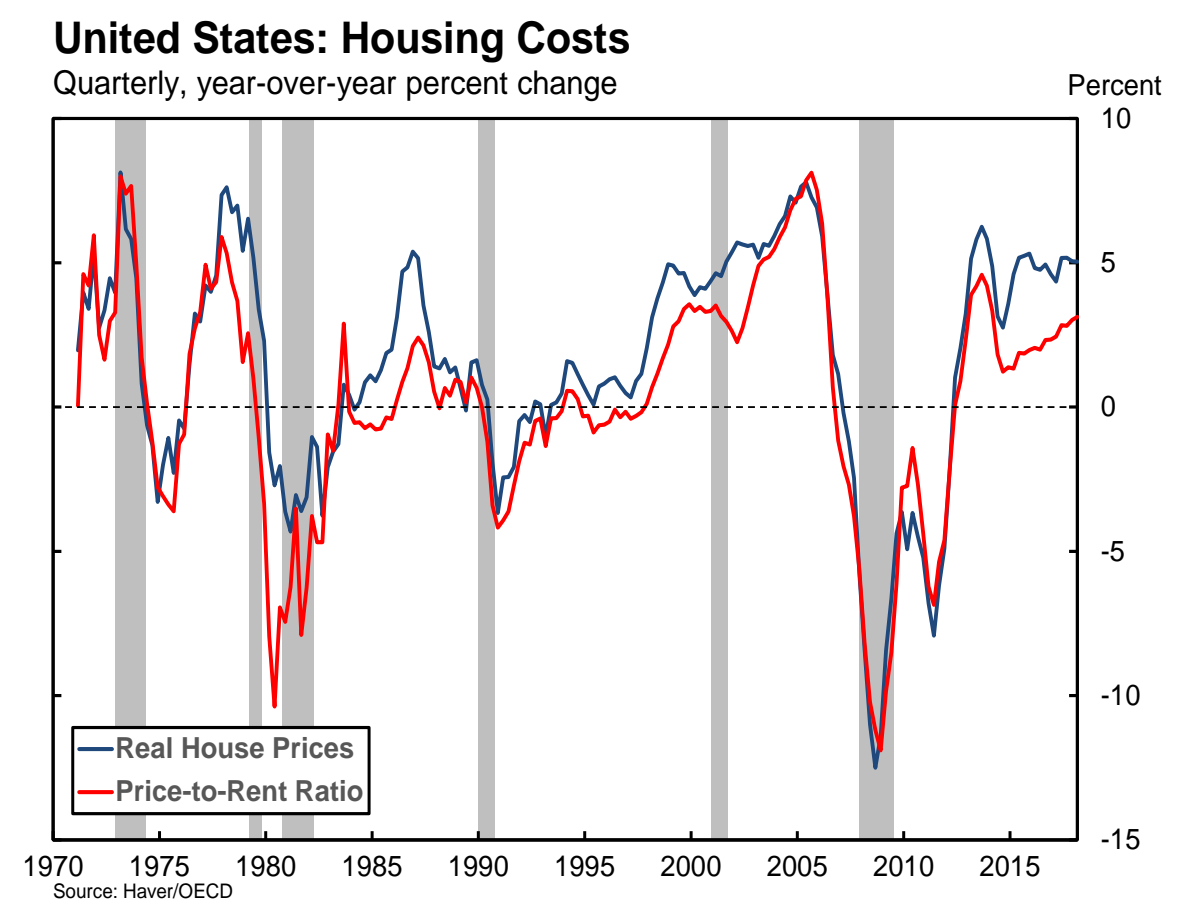

Figure 1. The real house prices and the price-to-rent ratio in the United States. 


\section{Changes in House Prices vs. the Price-to-Rent Ratio}

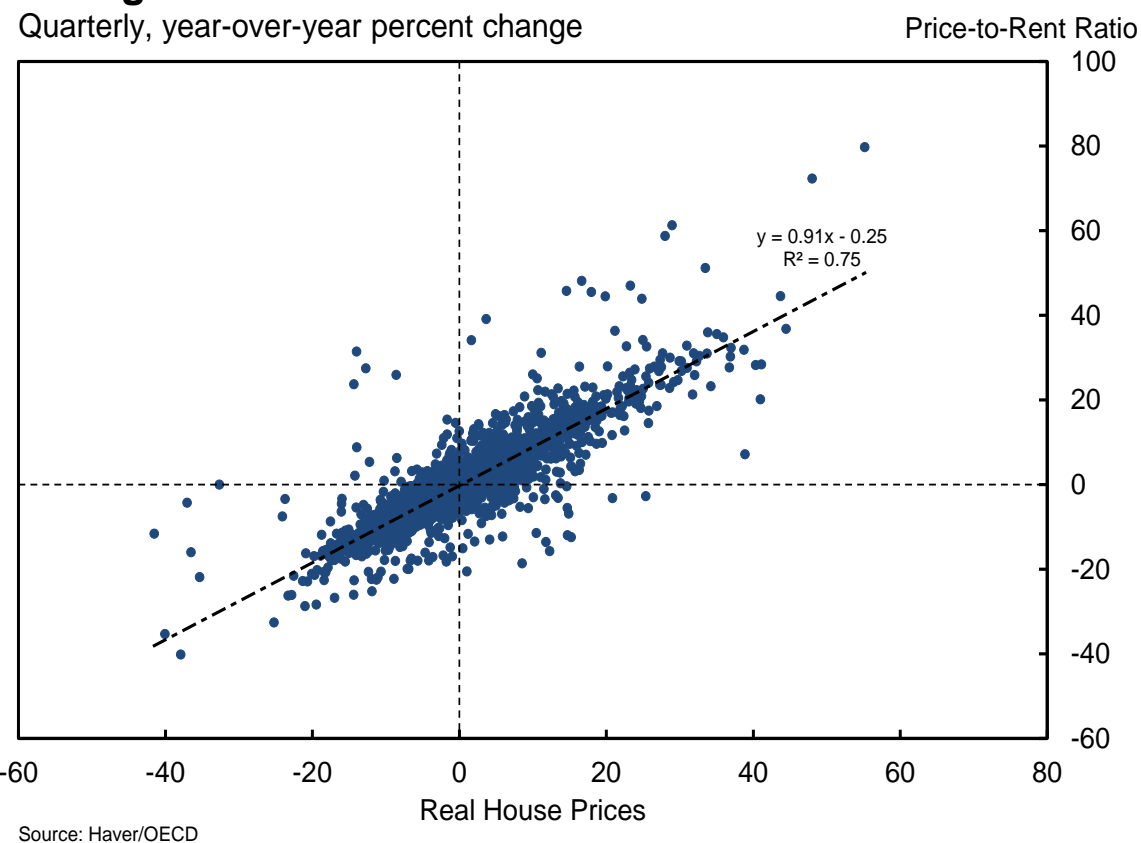

Figure 2. The real house prices and the price-to-rent ratio in OECD countries 


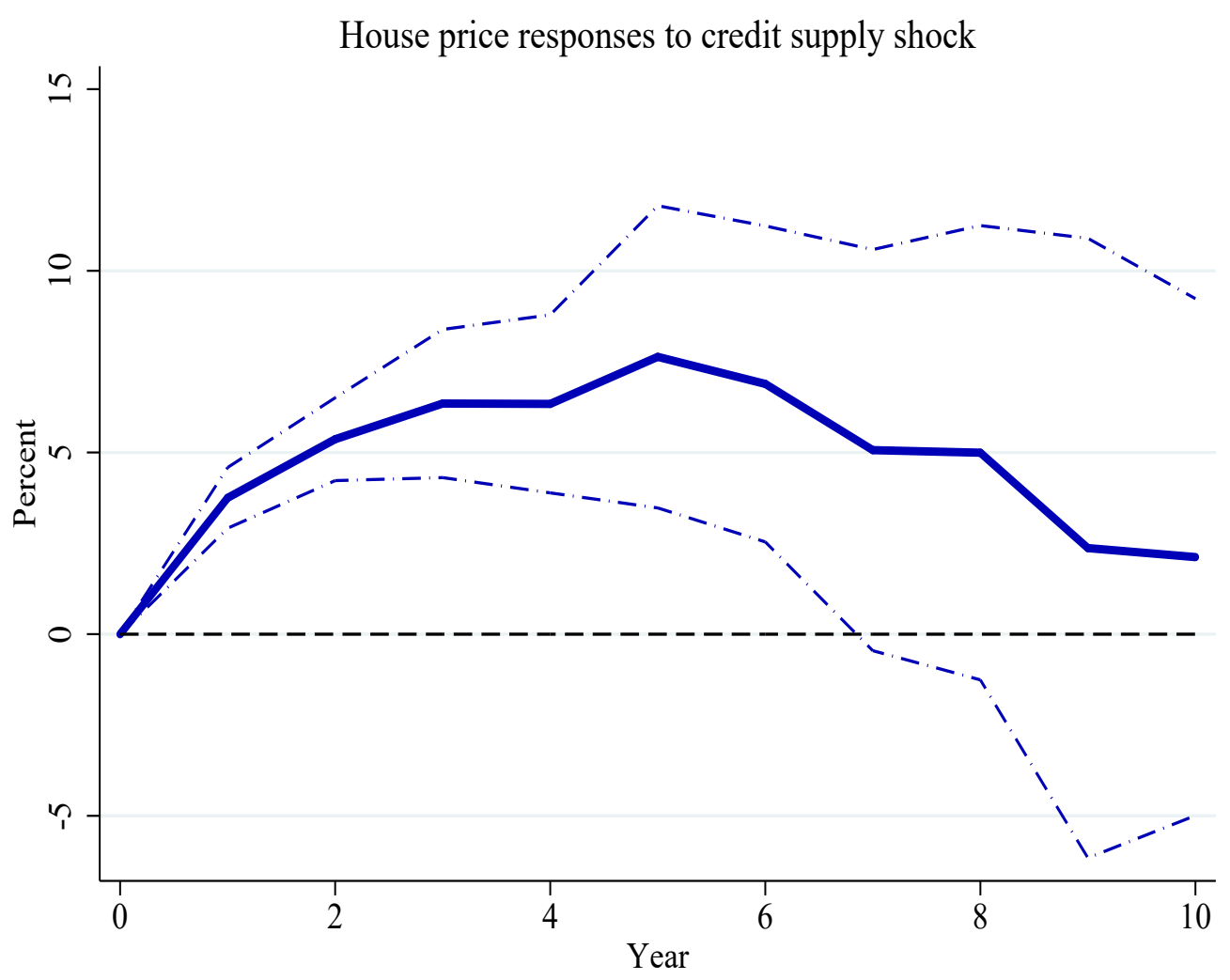

Figure 3. The dynamic responses of the house price to a positive credit supply shock. 


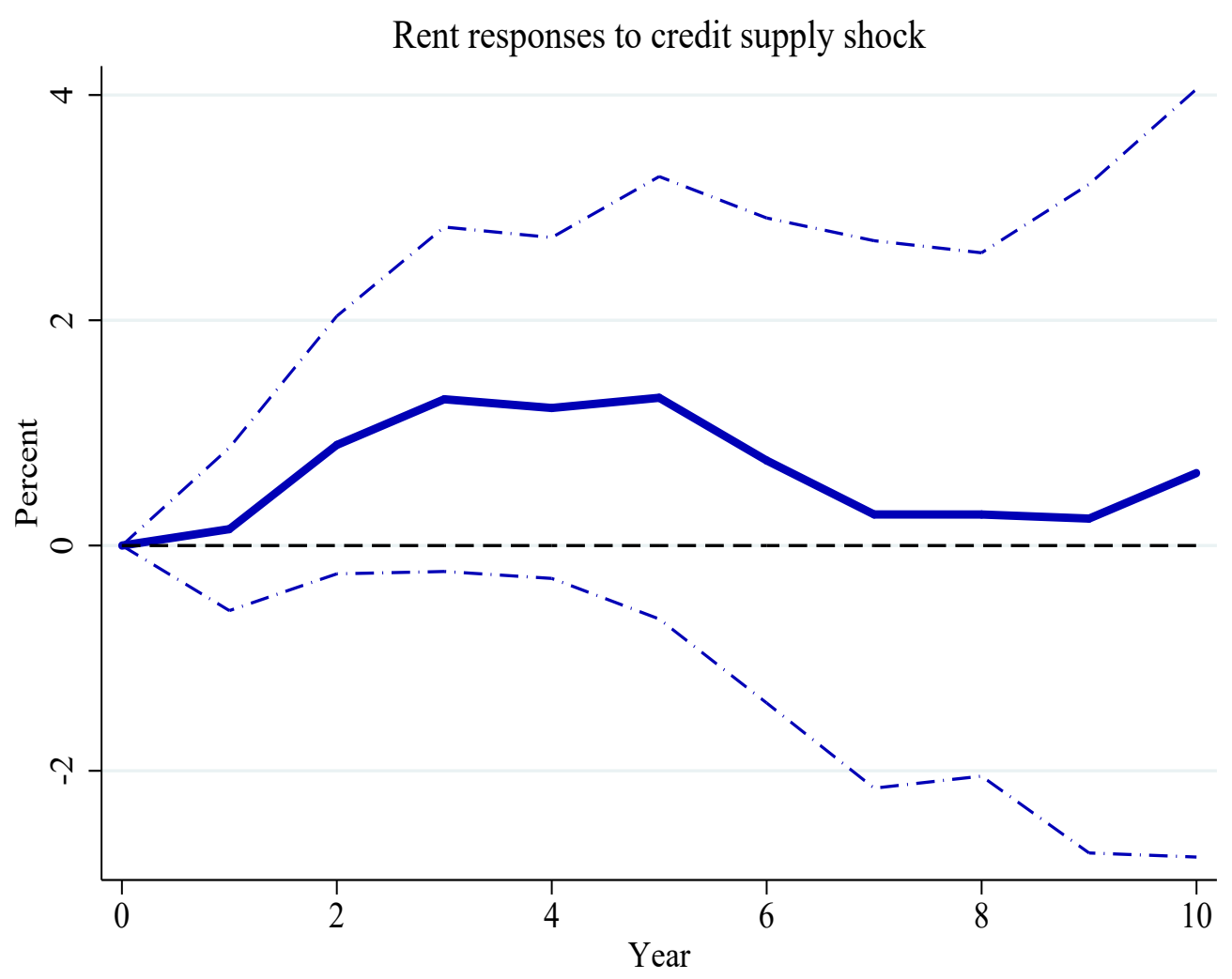

Figure 4. The dynamic responses of the rent to a positive credit supply shock. 


\section{Appendix}

Appendix A. A heterogeneous-Agent model With endogenous labor SUPPLY AND CAPITAL ACCUMULATION

This section shows that the benchmark heterogeneous-agent model that we presented in Section III can be generalized to incorporate endogenous labor supply and capital accumulation.

\section{Appendix B. Proofs of propositions}

\section{B.1. Proof of Proposition IV.3.}

\section{B.2. Proof of Proposition IV.5.}

\section{Appendix C. Data And some REGRESSiOn RESUlts}

The data that we have used for the local projections analysis in Section IV.5 include the household debt-to-GDP ratios, the mortgage interest rate spreads, the house prices, and the rents from 25 advanced economies. The household debt-to-GDP and the mortgage spreads are the same as those used by Mian et al. (2017). The house prices and the rents are taken from the OECD Main Economic Indicators through Haver Analytics. The rent data in Haver are in nominal terms, and we convert them into real terms using the consumer price index in each country (or the Harmonized Index of Consumer Prices for the European countries in our sample).

Table A1 presents some summary statistics of the data.

Table A2 presents the first-stage regression results, that is, the regression of the household debt-to-GDP ratio on the low mortgage spread dummy. 
TABLE A1. Summary of countries in the sample and key statistics

\begin{tabular}{|c|c|c|c|c|c|c|c|c|c|}
\hline Country & Start Year & $\operatorname{Mean}\left(\Delta D^{H H}\right)$ & $\operatorname{SD}\left(\Delta D^{H H}\right)$ & Mean $(s p r)$ & $\mathrm{SD}(s p r)$ & $\operatorname{Mean}(\Delta \ln (P))$ & $\mathrm{SD}(\Delta \ln (P))$ & $\operatorname{Mean}(\Delta \ln (R))$ & $\mathrm{SD}(\Delta \ln (R))$ \\
\hline Australia & 1979 & 2.22 & 2.58 & 1.14 & 1.65 & 3.19 & 6.60 & 0.56 & 2.03 \\
\hline Austria & 1997 & 0.69 & 1.30 & 0.98 & 0.54 & 1.62 & 2.82 & 1.09 & 2.05 \\
\hline Belgium & 1982 & 0.86 & 1.13 & 0.94 & 0.71 & 2.40 & 4.15 & 0.46 & 1.38 \\
\hline Canada & 1971 & 1.44 & 2.40 & 2.10 & 0.72 & 2.51 & 6.28 & -1.23 & 2.17 \\
\hline Czech Rep. & 2003 & 2.06 & 1.21 & 1.40 & 0.61 & -2.88 & 2.71 & 2.98 & 4.85 \\
\hline Denmark & 1996 & 3.65 & 4.06 & 0.31 & 0.52 & 2.87 & 7.90 & 0.58 & 0.77 \\
\hline Finland & 1981 & 1.22 & 2.47 & -0.33 & 1.28 & 2.19 & 9.40 & 0.09 & 3.57 \\
\hline France & 1979 & 1.10 & 1.22 & 0.36 & 0.85 & 2.04 & 5.44 & 0.82 & 1.37 \\
\hline Germany & 1972 & 0.50 & 1.82 & 0.98 & 0.69 & -0.30 & 2.39 & 0.39 & 1.67 \\
\hline Greece & 2000 & 4.00 & 2.18 & 1.23 & 0.36 & 0.06 & 8.67 & -0.40 & 2.79 \\
\hline Hungary & 2000 & 2.14 & 3.21 & 3.76 & 2.56 & -7.07 & 5.03 & 1.46 & 3.32 \\
\hline Ireland & 2004 & 5.01 & 8.46 & 0.54 & 0.73 & -4.10 & 11.50 & 3.08 & 18.87 \\
\hline Italy & 1996 & 1.59 & 1.16 & 1.52 & 1.06 & 0.57 & 5.20 & 0.62 & 1.67 \\
\hline Japan & 1981 & 0.57 & 1.94 & 0.64 & 0.80 & -0.19 & 4.02 & 0.46 & 1.20 \\
\hline Korea, Rep. & 2001 & 2.86 & 3.28 & -0.04 & 0.19 & 2.06 & 4.87 & -0.38 & 1.69 \\
\hline Mexico & 2005 & 0.51 & 0.65 & 7.26 & 0.78 & 0.01 & 2.07 & -1.44 & 0.83 \\
\hline Netherlands & 1992 & 3.76 & 2.73 & 1.24 & 0.72 & 3.16 & 6.17 & 1.17 & 1.65 \\
\hline Norway & 1988 & 0.56 & 3.44 & 1.14 & 1.16 & 2.88 & 7.93 & 0.87 & 1.38 \\
\hline Poland & 2003 & 2.18 & 2.46 & 0.96 & 0.87 & -5.20 & 1.86 & 0.77 & 1.52 \\
\hline Portugal & 1991 & 3.50 & 2.49 & 1.56 & 2.09 & -1.22 & 4.03 & 1.05 & 3.08 \\
\hline Spain & 1982 & 1.80 & 2.69 & 1.01 & 1.37 & 3.01 & 9.87 & 0.63 & 2.13 \\
\hline Sweden & 1987 & 1.19 & 2.83 & 0.32 & 0.58 & 3.35 & 7.20 & 1.93 & 3.90 \\
\hline Switzerland & 2001 & 1.25 & 3.22 & 0.98 & 0.58 & 2.91 & 2.88 & 0.87 & 0.88 \\
\hline U.K. & 1974 & 1.55 & 2.52 & 0.70 & 0.67 & 2.24 & 9.31 & 1.61 & 3.13 \\
\hline U.S. & 1965 & 0.69 & 2.21 & 1.74 & 0.54 & 1.22 & 4.19 & 0.66 & 1.48 \\
\hline
\end{tabular}

Notes: This table lists the 25 countries and the years covered in the first-stage regression. The variable $\Delta D^{H H}$ denotes the household debt-to-GDP ratio, spr denotes the mortgage spread, which is difference between the mortgage interest rate and the 10-year sovereign bond yield, $\Delta \ln (P)$ denotes the year-over-year log-changes in the house price, and $\Delta \ln (R)$ denotes the year-over-year log-changes in the rent. 
TABLE A2. First-stage regression: Dependent variable is $\Delta D_{i t}^{H H}$

\begin{tabular}{|c|c|c|}
\hline & $\begin{array}{c}\text { Real Rent } \\
\text { (1) }\end{array}$ & $\begin{array}{c}\text { Real Housing Prices } \\
(2)\end{array}$ \\
\hline \multirow[t]{2}{*}{$I_{i t}^{M S}$} & $0.57^{* * *}$ & $0.60^{* * *}$ \\
\hline & $(0.19)$ & $(0.19)$ \\
\hline \multirow[t]{2}{*}{$\Delta D_{i, t-1}^{H H}$} & $0.37^{* * *}$ & $0.36^{* * *}$ \\
\hline & $(0.06)$ & $(0.06)$ \\
\hline \multirow[t]{2}{*}{$\Delta D_{i, t-2}^{H H}$} & 0.06 & 0.07 \\
\hline & $(0.06)$ & $(0.06)$ \\
\hline \multirow[t]{2}{*}{$\Delta D_{i, t-3}^{H H}$} & $0.11^{* * *}$ & $0.12^{* * *}$ \\
\hline & $(0.04)$ & $(0.04)$ \\
\hline \multirow[t]{2}{*}{$\Delta D_{i, t-4}^{H H}$} & 0.03 & 0.04 \\
\hline & $(0.08)$ & $(0.08)$ \\
\hline \multirow[t]{2}{*}{$\Delta D_{i, t-5}^{H H}$} & -0.08 & -0.08 \\
\hline & $(0.10)$ & $(0.10)$ \\
\hline \multirow[t]{2}{*}{$\Delta D_{i, t-6}^{H H}$} & 0.04 & 0.03 \\
\hline & $(0.08)$ & $(0.08)$ \\
\hline \multirow{2}{*}{$\Delta D_{i, t-7}^{H H}$} & $-0.16^{* * *}$ & $-0.15^{* * *}$ \\
\hline & $(0.05)$ & $(0.05)$ \\
\hline \multirow[t]{2}{*}{$\Delta D_{i, t-8}^{H H}$} & -0.10 & -0.09 \\
\hline & $(0.07)$ & $(0.07)$ \\
\hline \multirow[t]{2}{*}{$\Delta D_{i, t-9}^{H H}$} & $-0.17^{* * *}$ & $-0.18^{* * *}$ \\
\hline & $(0.05)$ & $(0.05)$ \\
\hline \multirow[t]{2}{*}{$\Delta D_{i, t-10}^{H H}$} & 0.02 & 0.02 \\
\hline & $(0.04)$ & $(0.04)$ \\
\hline Observations & 477 & 464 \\
\hline F-Stat & 104.22 & 78.54 \\
\hline
\end{tabular}

Notes: This table shows the first-stage regression results for the local projections model specified in (55). The two columns correspond to the two different local projection specifications, one for the rent and the other for the house price. The first-stage regression in each case regress the log-growth rate of the household debt-to-GDP ratio $\Delta D_{i t}^{H H}$ in country $i$ and year $t$ on its own lags and also on the instrumental variable, which is the mortgage spread dummy $I_{i t}^{M S}$ that equals one if the mortgage spread is below its median and zero otherwise. 


\section{Appendix D. Heterogeneity in InCOME}

In our benchmark model, we assume that the source of heterogeneity lies in the agent's tastes for housing. Idiosyncratic taste shocks give rise to differences in the marginal utility of housing across agents. Our framework with heterogenous marginal utilities, combined with credit constraints, provides a microeconomic foundation for housing demand shocks. More importantly, it gives rise to a mechanism that can potentially generate the observed large fluctuations in the price-to-rent ratio.

The main insights, however, do not hinge upon the particular way of modeling heterogeneity. We now consider a different type of heterogeneity. Instead of assuming idiosyncratic preference shocks, we consider idiosyncratic income shocks. We show that all the main results obtained above carry over to this alternative setup.

Consider a household family with a continuum of members. All members enjoy the same consumption $c_{t}$. Each member gets a transfer payment $a_{t}$ from the family for purchasing houses in the decentralized housing market. Before their house purchase decisions, they each receives an idiosyncratic shock $\omega_{t}$ so that their effective net worth is $\omega_{t} a_{t}$. Since households with different realizations of $\omega_{t}$ make different house purchasing decisions, the housing services in the utility function for each member are indexed by $\omega_{t}$. The household utility function is given by

$$
\mathbb{E}_{0} \sum_{t=0}^{\infty} \beta^{t}\left[\log c_{t}+\varphi \int_{0}^{\infty} \frac{\left[h_{t}\left(\omega_{t}\right)\right]^{1-\theta}}{1-\theta} d F\left(\omega_{t}\right)\right]
$$

where $h_{t}\left(\omega_{t}\right)$ denotes housing held by the household member with the shock $\omega_{t}$, drawn from the distribution $F(\omega)$. All the other variables and parameters have the same interpretations as in the benchmark model.

The family faces the flow budget constraint

$$
c_{t}+a_{t}=y_{t}+q_{t} \int h_{t-1}\left(\omega_{t-1}\right) d F\left(\omega_{t-1}\right)-\int b_{t-1}\left(\omega_{t-1}\right) d F\left(\omega_{t-1}\right),
$$

where $y_{t}$ denotes endowment (or labor income), $q_{t}$ denotes the house price, and $b_{t-1}\left(\omega_{t-1}\right)$ denotes the last-period borrowing of the member with idiosyncratic income shock $\omega_{t-1}$.

In the decentralized housing markets, the household member with shock $\omega_{t}$ finances house purchases with both internal funds $\omega_{t} a_{t}$ and external debt $b\left(\omega_{t}\right)$, subject to the flow-of-funds constraint

$$
q_{t} h_{t}\left(\omega_{t}\right) \leq \omega_{t} a_{t}+\frac{b_{t}\left(\omega_{t}\right)}{R_{t}}
$$


and the borrowing constraint

$$
\frac{b_{t}\left(\omega_{t}\right)}{R_{t}} \leq \kappa_{t} q_{t} h_{t}\left(\omega_{t}\right)
$$

where $R_{t}$ denotes the risk-free interest rate and $\kappa_{t}$ denotes the loan-to-value ratio, which is common for all borrowers.

Denote by $\lambda_{t}, \eta_{t}\left(\omega_{t}\right)$, and $\pi_{t}\left(\omega_{t}\right)$ the Lagrangian multiplers associated with the constraints (57), (58), and (59), respectively. The first order condition with respect to $c_{t}$ is given by

$$
\frac{1}{c_{t}}=\lambda_{t}
$$

The first order condition with respect to $a_{t}$ implies

$$
\lambda_{t}=\int \eta_{t}\left(\omega_{t}\right) d F\left(\omega_{t}\right)
$$

The first order condition with respect to $h_{t}\left(\omega_{t}\right)$ is given by

$$
\eta_{t}\left(\omega_{t}\right) q_{t}=\varphi\left[h_{t}(\omega)\right]^{-\theta}+\beta \mathbb{E}_{t} \lambda_{t+1} q_{t+1}+\kappa_{t} q_{t} \pi_{t}\left(\omega_{t}\right)
$$

The first order condition with respect to $b_{t}\left(\omega_{t}\right)$ is

$$
\frac{1}{R_{t}} \eta_{t}\left(\omega_{t}\right)=\beta E_{t} \lambda_{t+1}+\frac{1}{R_{t}} \pi_{t}\left(\omega_{t}\right)
$$

These optimizing conditions have similar interpretations as in the benchmark model.

Aggregating the binding flow-of-funds constraints across all members, we obtain

$$
\int_{0}^{\infty} q_{t} h_{t}\left(\omega_{t}\right) d F\left(\omega_{t}\right)=a_{t} \int \omega_{t} d F\left(\omega_{t}\right)+\int \frac{b_{t}\left(\omega_{t}\right)}{R_{t}} d F\left(\omega_{t}\right)
$$

Imposing the market clearing conditions that $\int h_{t}(\omega) d F(\omega)=1$ and that $\int b_{t}(\omega) d F(\omega)=$ 0 , along with the normalization assumption that $\int \omega_{t} d F\left(\omega_{t}\right)=1$, we have

$$
q_{t}=a_{t}
$$

Notice that for housing member with $\omega_{t}$ such that the borrowing constraint does not bind, $\pi_{t}\left(\omega_{t}\right)=0$ and hence $\eta_{t}\left(\omega_{t}\right)=\beta R_{t} E_{t} \lambda_{t+1}$, equaiton (62), then suggests that $\varphi\left[h_{t}(\omega)\right]^{-\theta}$ are the same for members with $\pi_{t}\left(\omega_{t}\right)=0$. Intuitively, since each member has the same utility function with respect to housing, but differs ex post in their total wealth. Member with lower $\omega_{t}$ will be more likely to face a binding borrowing constraint. Hence there exist an cut-off $\omega_{t}^{*}$, such that the liquidity constraint (59) binds if and only if $\omega_{t}<\omega_{t}^{*}$. It immediately follows that $h_{t}(\omega)=\frac{\omega_{t}}{1-\kappa_{t}}$ for if $\omega_{t}<\omega_{t}^{*}$ by the the liquidity constraint (59), and $h_{t}\left(\omega_{t}\right)=\frac{\omega_{t}^{*}}{1-\kappa_{t}}$ if $\omega_{t} \geq \omega_{t}^{*}$ by recalling that members have the same housing units if their constraint (59) does not bind. The following proposition summarize $h_{t}\left(\omega_{t}\right), \eta_{t}\left(\omega_{t}\right)$ and $\pi_{t}\left(\omega_{t}\right)$. 
Proposition 1. There exist an unique cut-off $\omega_{t}^{*}$ such that the borrowing constraint (59) binds if and only if $\omega_{t}<\omega_{t}^{*}$. The housing demand for each member is given by

$$
h_{t}\left(\omega_{t}\right)=\left\{\begin{array}{ll}
\frac{\omega_{t}^{*}}{1-\kappa_{t}} & \text { if } \omega_{t} \geq \omega_{t}^{*} \\
\frac{\omega_{t}}{1-\kappa_{t}} & \text { if } \omega_{t}<\omega_{t}^{*}
\end{array}\right\}
$$

and the Lagrangian mutipliers are given by

$$
\begin{gathered}
\eta_{t}\left(\omega_{t}\right)=\left\{\begin{array}{cc}
R_{t} \beta E_{t} \lambda_{t+1} & \text { if } \omega_{t} \geq \omega_{t}^{*} \\
R_{t} \beta E_{t} \lambda_{t+1}+\frac{1}{q_{t}}\left(1-\kappa_{t}\right)^{\theta-1}\left[\left(\omega_{t}\right)^{-\theta}-\left(\omega_{t}^{*}\right)^{-\theta}\right] & \text { if } \omega_{t}^{j}<\omega_{t}^{*}
\end{array}\right\} . \\
\pi_{t}\left(\omega_{t}\right)=\left\{\begin{array}{cc}
0 & \text { if } \omega_{t} \geq \omega_{t}^{*} \\
\frac{1}{q_{t}}\left(1-\kappa_{t}\right)^{\theta-1}\left[\left(\omega_{t}\right)^{-\theta}-\left(\omega_{t}^{*}\right)^{-\theta}\right] & \text { if } \omega_{t}<\omega_{t}^{*}
\end{array}\right\} .
\end{gathered}
$$

Proof. The proof is similar to the case with idiosyncratic shocks. It is easy to verify

With the above proposition, equation (D.6) becomes

$$
\lambda_{t}=R_{t} \beta E_{t} \lambda_{t+1}+\frac{\varphi}{q_{t}}\left(1-\kappa_{t}\right)^{\theta-1} \int_{\omega_{\min }}^{\omega_{t}^{*}}\left[\omega^{-\theta}-\omega_{t}^{*-\theta}\right] f(\omega) d \omega .
$$

The intuition for equation (D.13) is as follows. One extra dollar increases in $a_{t}$ reduce consumption by one unit in period $t$ and hence costs $\lambda_{t}$ utility in period $t$. This one dollar will be saved by the family member if his borrowing constraint does not bind yields $R_{t}$ dollar for the family in the next period $t+1$ and hence add $R_{t} \beta E_{t} \lambda_{t+1}$ utility. If the family member borrowing constraint binds for $\omega_{t}>\omega_{t}^{*}$. This one dollar can allow the family member to purchase $\frac{1}{q_{t}} \frac{1}{1-\kappa_{t}}$ unit of housing, and enjoying additional marginal utility $h_{t}^{-\theta}\left(\omega_{t}\right)-h_{t}^{-\theta}\left(\omega_{t}^{*}\right)=\left[\frac{\omega_{t}}{1-\kappa_{t}}\right]^{-\theta}-\left[\frac{\omega_{t}^{*}}{1-\kappa_{t}}\right]^{-\theta}$ for $\omega_{t} \leq \omega_{t}^{*}$. Aggregating all possible realization of $\omega_{t}$ yields the second term on the right hand side of equation (D.13).

Using the relations in Equations (D.11) and (D.12), the optimizing housing decision for the marginal agent implies that

$$
\varphi\left[\frac{\omega_{t}^{*}}{1-\kappa_{t}}\right]^{-\theta}+\beta E_{t} \lambda_{t+1} q_{t+1}=q_{t} R_{t} \beta E_{t} \lambda_{t+1}
$$

The marginal family member has two choices: he can exhaust his borrowing limit and consume to the maximum and hence the maximum housing he can purchase is $\omega_{t}^{*} a_{t} / q_{t}\left(1-\kappa_{t}\right)=\frac{\omega_{t}^{*}}{1-\kappa_{t}}$, the last unit of housing yields utility $\varphi\left[\frac{\omega_{t}^{*}}{1-\kappa_{t}}\right]^{-\theta}$ from housing service and it can be sold at $q_{t+1}$ in the next period and bring $\beta E_{t} \lambda_{t+1} q_{t+1}$ additional utility; or he can save the value of the last unit of house in the risk free rate asset, it yields $q_{t} R_{t}$ in period $\mathrm{t}+1$ and $q_{t} R_{t} \beta E_{t} \lambda_{t+1}$ in term of utility. These two must be the same. 
We now decide how to determine the cutoff $\omega_{t}^{*}$. Housing market clearing condition implies

or

$$
\int_{\omega_{t}^{*}}^{\infty} \omega_{t}^{*} /\left(1-\kappa_{t}\right)+\int_{\omega_{\min }}^{\omega_{t}^{*}} \omega /\left(1-\kappa_{t}\right) f(\omega) d \omega=1
$$

$$
\int_{\omega_{\min }}^{\infty} \min \left(\omega, \omega_{t}^{*}\right) f(\omega) d \omega=1-\kappa_{t}
$$

which define an implicit function of $\omega_{t}^{*}=\omega^{*}\left(\kappa_{t}\right)$. To ensure an interior solution we assume $\kappa_{t}<1-\omega_{\min }$.

$$
\begin{aligned}
\xi_{t}= & \omega_{t}^{*-\theta}\left(1-\kappa_{t}\right)^{\theta} \\
& \left.+\left[\left(1-\kappa_{t}\right)\right]^{\theta-1} \int_{\omega_{\min }}^{\omega_{t}^{*}}\left[\omega^{-\theta}-\omega_{t}^{*-\theta}\right] f(\omega) d \omega\right]
\end{aligned}
$$

Finally equation (D.13) and (D.14) yields

$$
\lambda_{t} q_{t}=\varphi\left[\frac{\omega_{t}^{*}}{1-\kappa_{t}}\right]^{-\theta}+\beta E_{t} \lambda_{t+1} q_{t+1}+\varphi\left(1-\kappa_{t}\right)^{\theta-1} \int_{\omega_{\min }}^{\omega_{t}^{*}}\left[\omega^{-\theta}-\omega_{t}^{*-\theta}\right] f(\omega) d \omega .
$$

We now is ready to establish some equivalence between our hetergenous-agent model with homegenous-agent model. We have the following proposition. Similarly we rearrange the above equation as

$$
\lambda_{t} q_{t}=\varphi \mathbb{E}\left[h^{-\theta}\left(\omega_{t}\right)\right]+\beta E_{t} \lambda_{t+1} q_{t+1}+\frac{\kappa_{t}}{1-\kappa_{t}} \int_{\omega_{\min }}^{\omega_{t}^{*}}\left[h^{-\theta}\left(\omega_{t}\right)-h^{-\theta}\left(\omega_{t}^{*}\right)\right] f(\omega) d \omega
$$

The interpretation is similar as in the benchmark model.

Proposition 2. The housing price $q_{t}$ in this hetergenous-agent economy has the same equilibrium path as the homegous-agent model with $\varphi_{t}=\varphi \xi_{t}$.

Proof. The proof is straight-forward.

\section{D.1. The effect of down-payment ratio on housing prices. We now examine}

the effect of down payment ratio on housing price. First (D.15), implies

$$
\frac{\partial \omega_{t}^{*}}{\partial \kappa_{t}}=-\frac{1}{1-F\left(\omega_{t}^{*}\right)}<0
$$

Hence a lower down-payment implies a lower cut-off and hence a smaller probability of being liquidity constraint. However the effect on housing price is more complicate. We first look at the steady-state ratio between $q$, and $\kappa$ by expressing

$$
q=\frac{\varphi \omega^{*-\theta}(1-\kappa)^{\theta}}{\beta} \frac{1}{R-1},
$$


by equation (D.14). Namely the the housing price is a discounted price of the marginal household's marginal utility.

Using the relationship between $\omega^{*}$ and $\kappa$ we have

$$
\begin{aligned}
\omega^{*-\theta}(1-\kappa)^{\theta} & =\omega^{*-\theta}\left[\int_{\omega_{t}^{*}}^{\infty} \omega_{t}^{*} f(\omega) d \omega+\int_{\omega_{\min }}^{\omega_{t}^{*}} \omega f(\omega) d \omega\right]^{\theta} \\
& =\left[\int_{\omega^{*}}^{\infty} f(\omega) d \omega+\int_{\omega_{\min }}^{\omega_{t}^{*}} \frac{\omega}{\omega^{*}} f(\omega) d \omega\right]^{\theta} \\
& =\left[\int_{\omega_{\min }}^{\infty} \min \left(1, \frac{\omega}{\omega^{*}}\right) f(\omega) d \omega\right]^{\theta},
\end{aligned}
$$

which is decreasing in $\omega^{*}$ hence increasing in $\kappa$. This is very intuitively, since the model the poor household is liquidity constraint. A lower down-payment will allow the poor household to purchase more housing, and since the poor household enjoy a higher marginal utility (decreasing marginal utility in housing), so given the interest rate, so the housing price will increase. However there is a general equilibrium effect on interest rate too. The risk free rate $R$ is also affected by $\kappa$ through

$$
R=\frac{1}{\beta}-\frac{\varphi[(1-\kappa)]^{\theta-1} \int_{\omega_{\min }}^{\omega^{*}}\left[\omega^{-\theta}-\omega^{*-\theta}\right] f(\omega) d \omega}{q / c}
$$

Notice for $\theta \geq 1, R$ is also increasing in $\kappa$. And for regardless of $\theta$ as $\kappa$ approach to $1-\omega_{\min }, R$ approach $\frac{1}{\beta}$. A rise in interest rate will dampen the housing price. In general there will be a non-monotonic relationship between $\kappa$ and housing price. Instead to provide a general theory we now relax a special distribution to make this point.

\section{D.2. Example.}

D.2.1. Power Distribution. We first assume that $\omega$ follows a power distribution. Let $F(\omega)=\left[\frac{\omega}{\omega_{\max }}\right]^{\eta}$, again we have $\omega_{\max }=\frac{\eta+1}{\eta}$, so $\mathbb{E}(\omega)=1$. In this case we have

$$
\begin{aligned}
\int_{0}^{\omega_{\max } \min \left(\omega, \omega_{t}^{*}\right) f(\omega) d \omega} & =\omega_{t}^{*}\left[1-\left(\frac{\omega_{t}^{*}}{\omega_{\max }}\right)^{\eta}\right]+\frac{\eta}{\eta+1} \omega_{t}^{*}\left(\frac{\omega_{t}^{*}}{\omega_{\max }}\right)^{\eta} \\
& =\omega_{t}^{*}-\frac{1}{\eta+1} \omega_{t}^{*}\left(\frac{\omega_{t}^{*}}{\omega_{\max }}\right)^{\eta} \\
& =1-\kappa_{t}
\end{aligned}
$$


Assumption: $\eta>\theta$, so the term

$$
\begin{aligned}
& \left.\int_{\omega_{\min }}^{\omega_{t}^{*}}\left[\omega^{-\theta}-\omega_{t}^{*-\theta}\right] f(\omega) d \omega\right] \\
= & \int_{\omega_{\min }}^{\omega_{t}^{*}} \omega^{-\theta-1+\eta} \eta\left[\frac{1}{\omega_{\max }}\right]^{\eta} d \omega-\left[\frac{\omega_{t}^{*}}{\omega_{\max }}\right]^{\eta} \omega_{t}^{*-\theta} \\
= & {\left[\frac{1}{\omega_{\max }}\right]^{\eta} \frac{\theta}{\eta-\theta} \omega_{t}^{* \eta-\theta} }
\end{aligned}
$$

is well defined.

The resulting housing demand shock is given by

$$
\begin{aligned}
\xi_{t}= & \omega_{t}^{*-\theta}\left(1-\kappa_{t}\right)^{\theta} \\
& \left.+\left[\left(1-\kappa_{t}\right)\right]^{\theta-1} \int_{\omega_{\min }}^{\omega_{t}^{*}}\left[\omega^{-\theta}-\omega_{t}^{*-\theta}\right] f(\omega) d \omega\right] \\
= & \omega_{t}^{*-\theta}\left(1-\kappa_{t}\right)^{\theta}+\left[\left(1-\kappa_{t}\right)\right]^{\theta-1}\left[\frac{1}{\omega_{\max }}\right]^{\eta} \frac{\theta}{\eta-\theta} \omega_{t}^{* \eta-\theta}
\end{aligned}
$$

And the rents is

$$
\begin{aligned}
r_{h t} & =\int_{0}^{\omega_{t}^{*}}\left(\frac{\omega}{1-\kappa_{t}}\right)^{-\theta} f(\omega) d \omega+\int_{\omega_{t}^{*}}^{\omega_{\max }}\left(\frac{\omega_{t}^{*}}{1-\kappa_{t}}\right)^{-\theta} f(\omega) d \omega \\
& =\left(1-\kappa_{t}\right)^{\theta}\left[\left[\frac{1}{\omega_{\max }}\right]^{\eta} \frac{\theta}{\eta-\theta} \omega_{t}^{* \eta-\theta}+\left[1-\left(\frac{\omega_{t}^{*}}{\omega_{\max }}\right)^{\eta}\right] \omega_{t}^{*-\theta}\right] \\
& =\left(1-\kappa_{t}\right)^{\theta}\left[\omega_{t}^{*-\theta}+\left[\frac{1}{\omega_{\max }}\right]^{\eta} \frac{1}{\eta-\theta} \omega_{t}^{* \eta-\theta}\right]
\end{aligned}
$$

\section{APPENDIX E. UNCERTAINTY SHOCKS}

We now consider another type of shocks. For simplicity we now consider $\ell_{t}=0$. We assume that when individual household purchase the house, there is some uncertainty. Especially we now assume that housing purchase has made before individual observe its $\varepsilon_{t}$. Instead, we will assume that household will purchase housing based on a noisy signal $s_{t}$, drawn from an distribution function $F$ We assume that

$$
\varepsilon_{t}=\left\{\begin{array}{cc}
s_{t} & \text { with prob } p_{t} \\
s_{t}^{\prime} & \text { with prob } 1-p_{t}
\end{array}\right\}
$$


where $s_{t}^{\prime}$ is independently drawn from the same distribution function. The utility function of the individual hence changes to

$$
\begin{aligned}
& \mathbb{E}_{0} \sum_{t=0}^{\infty} \beta^{t}\left[\log c_{t}+\varphi \int_{0}^{\infty} \frac{\mathbb{E}\left[\varepsilon_{t}\left[h_{t}\left(s_{t}\right)\right]^{1-\theta} \mid s_{t}\right]}{1-\theta} d F\left(s_{t}\right)\right] \\
= & \mathbb{E}_{0} \sum_{t=0}^{\infty} \beta^{t}\left[\log c_{t}+\varphi \int_{0}^{\infty} \frac{\left(1-p_{t}+p_{t} s_{t}\right)\left[h_{t}\left(s_{t}\right)\right]^{1-\theta}}{1-\theta} d F\left(s_{t}\right)\right]
\end{aligned}
$$

The household family faces the budget constraint

$$
c_{t}+a_{t}=y_{t}+q_{t} \int h_{t-1}\left(s_{t-1}\right) d F\left(\varepsilon_{t-1}\right)-\int b_{t-1}\left(s_{t-1}\right) d F\left(s_{t-1}\right) .
$$

In the decentralized housing markets, a member with idiosyncratic shock signal $s_{t}$ finances his spending on new housing $q_{t} h_{t}\left(s_{t}\right)$ using both internal funds $a_{t}$ received from the family and external borrowing of $b_{t}\left(\varepsilon_{t}\right)$ at the interest rate $R_{t}$. The flow-offunds constraint for the household member $s_{t}$ is given by

$$
q_{t} h_{t}\left(s_{t}\right) \leq a_{t}+\frac{b_{t}\left(s_{t}\right)}{R_{t}} .
$$

As in Kiyotaki and Moore (1997), imperfect contract enforcement implies that the external debt cannot exceed a fraction of the collateral value. The homebuyer with $\varepsilon_{t}$ thus faces the collateral constraint

$$
\frac{b_{t}\left(s_{t}\right)}{R_{t}} \leq \kappa_{t} q_{t} h_{t}\left(s_{t}\right)
$$

where the loan-to-value ratio $\kappa_{t} \in[0,1]$ is exogenous and potentially time varying, representing shocks to credit conditions. And finally we have impose a no short-selling constraint

$$
h_{t}\left(s_{t}\right) \geq 0
$$

Denote by $\lambda_{t}, \eta_{t}\left(s_{t}\right), \pi_{t}\left(s_{t}\right)$ as the Lagrangian multiplers associated with the constraints (18), (19), (20), and (E.4) respectively.

The first order condition with respect to $c_{t}$ is given by

$$
\frac{1}{c_{t}}=\lambda_{t}
$$

The first order condition with respect to $a_{t}$ implies

$$
\lambda_{t}=\int \eta_{t}\left(s_{t}\right) d F\left(s_{t}\right) .
$$

A marginal unit of goods transferred to individual members for housing purchases reduces family consumption by one unit and hence the utility cost is $\lambda_{t}$. The utitlity 
gain from this transfer is the shadow value of newly purchased housing (i.e., $\eta_{t}\left(\varepsilon_{t}\right)$ ) averaged across all members.

The first order condition with respect to $h_{t}\left(s_{t}\right)$ yields

$$
\eta_{t}\left(s_{t}\right) q_{t}=\varphi \underbrace{\left(1-p_{t}+p_{t} s_{t}\right)}_{\mathbb{E}_{t}\left(\varepsilon_{t} \mid s_{t}\right)}\left[h_{t}\left(s_{t}\right)\right]^{-\theta}+\beta \mathbb{E}_{t} \lambda_{t+1} q_{t+1}+\kappa_{t} q_{t} \pi_{t}\left(s_{t}\right) .
$$

The first-order condition with respect to $b_{t}\left(s_{t}\right)$ is given by

$$
\eta_{t}\left(s_{t}\right)=\beta R_{t} \mathbb{E}_{t} \lambda_{t+1}+\pi_{t}\left(s_{t}\right) .
$$

Define $s_{t}^{*}=\inf \left\{s_{t}: \mid \frac{b_{t}\left(s_{t}\right)}{R_{t}}=\kappa_{t} q_{t} h_{t}\left(s_{t}\right)\right\}$. Then we have

$$
h_{t}\left(s_{t}\right)=\left\{\begin{array}{cc}
\frac{1}{1-\kappa_{t}} & s_{t} \geq s_{t}^{*} \\
\left(\frac{1-p_{t}+p_{t} s}{1-p_{t}+p_{t} s_{t}^{*}}\right)^{\frac{1}{\theta}} \frac{1}{1-\kappa_{t}} & s_{t}<s_{t}^{*}
\end{array}\right\}
$$

We then have $\left(1-\kappa_{t}\right) q_{t} \pi_{t}\left(s_{t}\right)=\varphi p_{t}\left(s_{t}-s_{t}^{*}\right)\left[\frac{1}{1-\kappa_{t}}\right]^{-\theta}$. Aggregating over $s_{t}$ and applies $\lambda_{t}=\int \eta_{t}\left(s_{t}\right) d F\left(s_{t}\right)$.

This leads to the following equilibrium housing price

$$
q_{t} \lambda_{t}=\mathbb{E}_{t} \beta \lambda_{t+1} q_{t+1}+\xi\left(\kappa_{t}, p_{t}\right),
$$

where the function $\xi_{t} \equiv \xi\left(\kappa_{t}, p_{t}\right)$ is given by

$$
\begin{aligned}
\xi\left(\kappa_{t}, p_{t}\right) \equiv & \underbrace{\varphi\left(1-\kappa_{t}\right)^{\theta}\left[\left(1-p_{t}\right)+p_{t} \mathbb{E} \max \left\{s, s_{t}^{*}\right\}\right]}_{\text {Average marginal utility }}+\underbrace{\frac{\kappa_{t}}{1-\kappa_{t}} p_{t} \int_{s_{t}^{*}}^{\varepsilon_{\max }}\left(1-\kappa_{t}\right)^{\theta} \varphi\left(s_{t}-s_{t}^{*}\right) d F\left(\varepsilon_{t}\right)}_{\text {liquidity premium }}, \\
& \int_{0}^{s_{t}^{*}}\left(\frac{1-p_{t}+p_{t} s}{1-p_{t}+p_{t} s_{t}^{*}}\right)^{\frac{1}{\theta}} \frac{1}{1-\kappa_{t}} d F(\varepsilon)+\int_{s_{t}^{*}}^{\varepsilon_{\max }} \frac{1}{1-\kappa_{t}} d F(\varepsilon)=1
\end{aligned}
$$

In the case $\theta=0$, we have

$$
\xi\left(\kappa_{t}, p_{t}\right) \equiv \underbrace{\varphi\left[\left(1-p_{t}\right)+p_{t} \mathbb{E}\left(s_{t}\right)\right]}_{\text {Average marginal utility }}+\underbrace{\frac{\kappa_{t}}{1-\kappa_{t}} p_{t} \int_{s_{t}^{*}}^{\varepsilon_{\max }}\left(1-\kappa_{t}\right)^{\theta} \varphi\left(s_{t}-s_{t}^{*}\right) d F\left(s_{t}\right)}_{\text {liquidity premium }}+p_{t} \int_{0}^{s_{t}^{*}}\left(s_{t}^{*}-s_{t}\right) d F\left(s_{t}\right)
$$

And the housing market clearing condition becomes

$$
\int_{s_{t}^{*}}^{\varepsilon_{\max }} \frac{1}{1-\kappa_{t}} d F(\varepsilon)=1
$$

Hence the cutoff $s_{t}^{*}$ is indepedent of $p_{t}$. Notice that the average MRS is a constant $\varphi\left[\left(1-p_{t}\right)+p_{t} \mathbb{E}\left(s_{t}\right)\right]=\varphi$, while the housing demand shock.

$$
\frac{\partial \xi\left(\kappa_{t}, p_{t}\right)}{\partial p_{t}} \equiv \frac{\kappa_{t}}{1-\kappa_{t}} \int_{s_{t}^{*}}^{\varepsilon_{\max }}\left(1-\kappa_{t}\right)^{\theta} \varphi\left(s_{t}-s_{t}^{*}\right) d F\left(s_{t}\right)+\int_{0}^{s_{t}^{*}}\left(s_{t}^{*}-s_{t}\right) d F\left(s_{t}\right)
$$


which increases with $p_{t}$. In other words, when uncertainty reduces, the housing price increases but the measured rents remain constant.

\section{Appendix F. Rental markets}

We now add a rental market for housing in our model. The purpose of doing this is to show that the imputed rental is a valid measurement of rents. We will introduce the rental market in a way so our extended model has minimum departure from our benchmark model. The expected utility function of the household is given by

$$
\mathbb{E}_{0} \sum_{t=0}^{\infty} \beta^{t}\left[\log c_{t}+\varphi \int_{0}^{\infty} \frac{\varepsilon_{t}\left[\ell_{t}+h_{t}\left(\varepsilon_{t}\right)\right]^{1-\theta}}{1-\theta} d F\left(\varepsilon_{t}\right)\right],
$$

where $\ell_{t}$ is total rental house. We assume that the family initially rent some apartments $\ell_{t}$ for each family member before their idiosyncratic shock is realized. Once the idiosyncratic shock is realized, each member decides how many additional unit that she/he want to purchase. So the family problem becomes

$$
c_{t}+a_{t}+r_{h t} \ell_{t}=y_{t}+q_{t} \int h_{t-1}\left(\omega_{t-1}\right) d F\left(\varepsilon_{t-1}\right)-\int b_{t-1}\left(\omega_{t-1}\right) d F\left(\omega_{t-1}\right)+r_{h t} \ell .
$$

We assume that the family owns $\ell$ unit of apartment. In the decentralized housing markets, a member with idiosyncratic shock $\varepsilon_{t}$ finances his spending on new housing $q_{t} h_{t}\left(\varepsilon_{t}\right)$ using both internal funds $a_{t}$ received from the family and external borrowing of $b_{t}\left(\varepsilon_{t}\right)$ at the interest rate $R_{t}$. The flow-of-funds constraint for the household member $\varepsilon_{t}$ is given by

$$
q_{t} h_{t}\left(\varepsilon_{t}\right) \leq a_{t}+\frac{b_{t}\left(\varepsilon_{t}\right)}{R_{t}}
$$

As in Kiyotaki and Moore (1997), imperfect contract enforcement implies that the external debt cannot exceed a fraction of the collateral value. The homebuyer with $\varepsilon_{t}$ thus faces the collateral constraint

$$
\frac{b_{t}\left(\varepsilon_{t}\right)}{R_{t}} \leq \kappa_{t} q_{t} h_{t}\left(\varepsilon_{t}\right)
$$

where the loan-to-value ratio $\kappa_{t} \in[0,1]$ is exogenous and potentially time varying, representing shocks to credit conditions. And finally we impose that

$$
h_{t}\left(\varepsilon_{t}\right) \geq 0
$$

Denote by $\lambda_{t}, \eta_{t}\left(\varepsilon_{t}\right), \pi_{t}\left(\varepsilon_{t}\right)$ and $\mu_{t}\left(\varepsilon_{t}\right)$ the Lagrangian multiplers associated with these above constraints, respectively. Then the first order condition with respect to $c_{t}$ is given by

$$
\frac{1}{c_{t}}=\lambda_{t}
$$


The first order condition with respect to $a_{t}$ implies

$$
\lambda_{t}=\int \eta_{t}\left(\varepsilon_{t}\right) d F\left(\varepsilon_{t}\right) .
$$

The first order condition with respect to $\ell_{t}$ implies

$$
r_{h t}=\frac{1}{\lambda_{t}} \varphi \int_{0}^{\infty} \varepsilon_{t}\left[\ell_{t}+h_{t}\left(\varepsilon_{t}\right)\right]^{-\theta} d F\left(\varepsilon_{t}\right)
$$

So indeed, the rental price is the expected MRS between housing and consumption. The first order conditions with he first order condition with respect to $a_{t}$ implies

$$
\lambda_{t}=\int \eta_{t}\left(\varepsilon_{t}\right) d F\left(\varepsilon_{t}\right)
$$

A marginal unit of goods transferred to individual members for housing purchases reduces family consumption by one unit and hence the utility cost is $\lambda_{t}$. The utitlity gain from this transfer is the shadow value of newly purchased housing (i.e., $\eta_{t}\left(\varepsilon_{t}\right)$ ) averaged across all members.

The first order condition with respect to $h_{t}\left(\varepsilon_{t}\right)$ yields

$$
\eta_{t}\left(\varepsilon_{t}\right) q_{t}=\varphi \varepsilon_{t}\left[\ell_{t}+h_{t}\left(\varepsilon_{t}\right)\right]^{-\theta}+\beta \mathbb{E}_{t} \lambda_{t+1} q_{t+1}+\kappa_{t} q_{t} \pi_{t}\left(\varepsilon_{t}\right)+\mu_{t}\left(\varepsilon_{t}\right) .
$$

The first-order condition with respect to $b_{t}\left(\varepsilon_{t}\right)$ is given by

$$
\eta_{t}\left(\varepsilon_{t}\right)=\beta R_{t} \mathbb{E}_{t} \lambda_{t+1}+\pi_{t}\left(\varepsilon_{t}\right)
$$

The solution to this problems can be characterized by two cutoffs. Intuitively speaking, a family member with very large $\varepsilon_{t}$ will wants to purchase housing as much as possible and family member with very small $\varepsilon_{t}$ will not want to purchase housing at all. We have the following proposition. Lemma F.1 below gives the solution for the equilibrium housing purchase $h_{t}\left(\varepsilon_{t}\right)$ as well as the cutoff point $\varepsilon_{t}^{*}$.

Lemma F.1. There exists a cutoff point $\varepsilon_{t}^{*}$ in the support of the distribution $F(\varepsilon)$, such that

$$
h_{t}\left(\varepsilon_{t}\right)=\left\{\begin{array}{cc}
\frac{1}{1-\kappa_{t}} & \text { if } \varepsilon_{t} \geq \varepsilon_{t}^{*} \\
\max \left\{\left(\frac{\varepsilon_{t}}{\varepsilon_{t}^{*}}\right)^{\frac{1}{\theta}}\left(\ell_{t}+\frac{1}{1-\kappa_{t}}\right)-\ell_{t}, 0\right\} & \text { otherwise }
\end{array}\right.
$$

In equilibrium $\ell_{t}=\ell$. Define $\varepsilon_{\ell t}^{*}$ as

$$
\varepsilon_{\ell t}^{*}=\left(\frac{\ell_{t}}{\ell_{t}+\frac{1}{1-\kappa_{t}}}\right)^{\theta} \varepsilon_{t}^{*}
$$


The cutoff point $\varepsilon_{t}^{*}$ is determined by

$$
\int_{\varepsilon_{\ell t}^{*}}^{\varepsilon_{t}^{*}}\left[\left(\frac{\varepsilon_{t}}{\varepsilon_{t}^{*}}\right)^{\frac{1}{\theta}}\left(\ell_{t}+\frac{1}{1-\kappa_{t}}\right)-\ell_{t}\right] f(\varepsilon) d \varepsilon+\int_{\varepsilon_{t}^{*}}^{\varepsilon_{\max }} \frac{1}{1-\kappa_{t}} f(\varepsilon) d \varepsilon=1
$$

Proof. For a household member with $\varepsilon_{t} \geq \varepsilon_{t}^{*}$, the borrowing constraint is binding and hence the flow of funds constraint yields

$$
h_{t}\left(\varepsilon_{t}\right)=\frac{a_{t}}{q_{t}\left(1-\kappa_{t}\right)}=\frac{1}{1-\kappa_{t}},
$$

which is independent of $\varepsilon_{t}$.

If $\varepsilon_{t}<\varepsilon_{t}^{*}$, then $\pi_{t}\left(\varepsilon_{t}\right)=0$. We have

$$
\eta_{t}\left(\varepsilon_{t}\right)=\beta R_{t} E_{t} \lambda_{t+1}=\eta_{t}\left(\varepsilon_{t}^{*}\right) \equiv \eta_{t}^{*}
$$

Furthermore, with $\pi_{t}\left(\varepsilon_{t}\right)=0$, Eq. (24) implies that

$$
\eta_{t}^{*} q_{t}=\varphi \varepsilon_{t}\left[\ell_{t}+h_{t}\left(\varepsilon_{t}\right)\right]^{-\theta}+\beta E_{t} \lambda_{t+1} q_{t+1}+\mu_{t}\left(\varepsilon_{t}\right)
$$

if $\mu_{t}\left(\varepsilon_{t}\right)=0$, then we must have

$$
\varphi \varepsilon_{t}\left[\ell_{t}+h_{t}\left(\varepsilon_{t}\right)\right]^{-\theta}=\varphi \varepsilon_{t}^{*}\left[\ell_{t}+h_{t}\left(\varepsilon_{t}^{*}\right)\right]^{-\theta}=\varphi \varepsilon_{t}^{*}\left(\ell_{t}+\frac{1}{1-\kappa_{t}}\right)^{-\theta} .
$$

Simple algebra yields that $h_{t}\left(\varepsilon_{t}\right)=\left(\frac{\varepsilon_{t}}{\varepsilon_{t}^{*}}\right)^{\frac{1}{\theta}}\left(\ell_{t}+\frac{1}{1-\kappa_{t}}\right)-\ell_{t}$. By the definition of $\varepsilon_{\ell t}^{*}$ we have $h_{t}\left(\varepsilon_{t}\right) \geq 0$ if $\varepsilon_{t} \geq \varepsilon_{\ell t}^{*}$. Finally, if $\varepsilon_{t}<\varepsilon_{\ell t}^{*}, h_{t}\left(\varepsilon_{t}\right)=0$. The housing market clearing condition then implies

$$
\int_{\varepsilon_{\ell t}^{*}}^{\varepsilon_{t}^{*}}\left[\left(\frac{\varepsilon_{t}}{\varepsilon_{t}^{*}}\right)^{\frac{1}{\theta}}\left(\ell_{t}+\frac{1}{1-\kappa_{t}}\right)-\ell_{t}\right] f(\varepsilon) d \varepsilon+\int_{\varepsilon_{t}^{*}}^{\varepsilon_{\max }} \frac{1}{1-\kappa_{t}} f(\varepsilon) d \varepsilon=1 .
$$

We now consider the price. We need an express for $\pi_{t}\left(\varepsilon_{t}\right)$ and $\mu_{t}\left(\varepsilon_{t}\right)$. We have the following Lemma.

Lemma F.2. The expression for $\pi_{t}\left(\varepsilon_{t}\right), \mu_{t}\left(\varepsilon_{t}\right)$ and price $q_{t}$ is given by

$$
\pi_{t}\left(\varepsilon_{t}\right)=\left\{\begin{array}{cc}
\frac{1}{1-\kappa_{t}} \varphi\left(\varepsilon_{t}-\varepsilon_{t}^{*}\right)\left[\ell_{t}+\frac{1}{1-\kappa_{t}}\right]^{-\theta} & \text { if } \varepsilon_{t} \geq \varepsilon_{t}^{*} \\
0 & \text { otherwise }
\end{array}\right.
$$

and

$$
\mu_{t}\left(\varepsilon_{t}\right)=\left\{\begin{array}{cl}
0 & \text { if } \varepsilon_{t} \geq \varepsilon_{\ell t}^{*} \\
\varphi\left(\varepsilon_{\ell t}^{*}-\varepsilon_{t}\right)\left[\ell_{t}\right]^{-\theta} & \text { otherwise }
\end{array}\right.
$$


and

$$
\begin{aligned}
\lambda_{t} q_{t}= & \varphi \int \varepsilon\left[\ell_{t}+h_{t}(\varepsilon)\right]^{-\theta} f(\varepsilon) d \varepsilon+\beta \mathbb{E}_{t} \lambda_{t+1} q_{t+1}+\kappa_{t} q_{t} \int \pi_{t}\left(\varepsilon_{t}\right) f(\varepsilon) d \varepsilon+\int \mu_{t}(\varepsilon) f(\varepsilon) d \varepsilon \\
= & \varphi \int \varepsilon\left[\ell_{t}+h_{t}(\varepsilon)\right]^{-\theta} f(\varepsilon) d \varepsilon+\beta \mathbb{E}_{t} \lambda_{t+1} q_{t+1}+\frac{\kappa_{t}}{1-\kappa_{t}} q_{t} \int_{\varepsilon_{t}^{*}}^{\varepsilon_{\max }} \varphi\left(\varepsilon_{t}-\varepsilon_{t}^{*}\right)\left[\ell_{t}+\frac{1}{1-\kappa_{t}}\right]^{-\theta} f(\varepsilon) d \varepsilon \\
& +\int_{0}^{\varepsilon_{\ell t}^{*}} \varphi\left(\varepsilon_{\ell t}^{*}-\varepsilon_{t}\right)\left[\ell_{t}\right]^{-\theta} f(\varepsilon) d \varepsilon .
\end{aligned}
$$

Let us define $\xi_{t}$ as

$\xi_{t}=\int \varepsilon\left[\ell_{t}+h_{t}(\varepsilon)\right]^{-\theta} f(\varepsilon) d \varepsilon+\frac{\kappa_{t}}{1-\kappa_{t}} \int_{\varepsilon_{t}^{*}}^{\varepsilon_{\max }} \varphi\left(\varepsilon_{t}-\varepsilon_{t}^{*}\right)\left[\ell_{t}+\frac{1}{1-\kappa_{t}}\right]^{-\theta} f(\varepsilon) d \varepsilon+\int_{0}^{\varepsilon_{\ell t}^{*}} \varphi\left(\varepsilon_{\ell t}^{*}-\varepsilon_{t}\right)\left[\ell_{t}\right]^{-\theta} f(\varepsilon) d$ where $\varepsilon_{t}^{*}$ and $\varepsilon_{\ell t}^{*}$ are given by

$$
\begin{gathered}
\int_{\varepsilon_{\ell t}^{*}}^{\varepsilon_{t}^{*}}\left[\left(\frac{\varepsilon_{t}}{\varepsilon_{t}^{*}}\right)^{\frac{1}{\theta}}\left(\ell_{t}+\frac{1}{1-\kappa_{t}}\right)-\ell_{t}\right] f(\varepsilon) d \varepsilon+\int_{\varepsilon_{t}^{*}}^{\varepsilon_{\max }} \frac{1}{1-\kappa_{t}} f(\varepsilon) d \varepsilon=1, \\
\varepsilon_{\ell t}^{*}=\left(\frac{\ell_{t}}{\ell_{t}+\frac{1}{1-\kappa_{t}}}\right)^{\theta} \varepsilon_{t}^{*} .
\end{gathered}
$$

Notice that when $\lim _{\ell_{t} \rightarrow 0}, \varepsilon_{\ell t}^{*} \rightarrow 0$ and we have

$$
\xi_{t}=\xi\left(\kappa_{t}\right) \equiv \underbrace{\varphi\left(1-\kappa_{t}\right)^{\theta} \mathbb{E} \max \left\{\varepsilon, \varepsilon_{t}^{*}\right\}}_{\text {Average marginal utility }}+\underbrace{\frac{\kappa_{t}}{1-\kappa_{t}} \int_{\varepsilon_{t}^{*}}^{\varepsilon_{\max }}\left(1-\kappa_{t}\right)^{\theta} \varphi\left(\varepsilon_{t}-\varepsilon_{t}^{*}\right) d F\left(\varepsilon_{t}\right)}_{\text {liquidity premium }} .
$$

Which is the same the as before. Notice that the rents now explicitly equal to

$$
\lim _{\ell_{t} \rightarrow 0} r_{h t}=\lim _{\ell_{t} \rightarrow 0} \int \varepsilon\left[\ell_{t}+h_{t}(\varepsilon)\right]^{-\theta} f(\varepsilon) d \varepsilon=\frac{1}{\lambda_{t}} \varphi\left(1-\kappa_{t}\right)^{\theta} \mathbb{E} \max \left\{\varepsilon, \varepsilon_{t}^{*}\right\} .
$$

With the help of power distribution, we can explicitly write down the expression for $r_{h t}$ and $q_{t}$ for the general cases. First the cutoff $\varepsilon_{t}^{*}$ is determined by

$$
\begin{gathered}
\int_{\varepsilon_{\ell t}^{*}}^{\varepsilon_{t}^{*}}\left[\left(\frac{\varepsilon_{t}}{\varepsilon_{t}^{*}}\right)^{\frac{1}{\theta}}\left(\ell_{t}+\frac{1}{1-\kappa_{t}}\right)-\ell_{t}\right] f(\varepsilon) d \varepsilon+\int_{\varepsilon_{t}^{*}}^{\varepsilon_{\max }} \frac{1}{1-\kappa_{t}} f(\varepsilon) d \varepsilon=1, \\
\varepsilon_{\ell t}^{*}=\left(\frac{\ell_{t}}{\ell_{t}+\frac{1}{1-\kappa_{t}}}\right)^{\theta} \varepsilon_{t}^{*} .
\end{gathered}
$$

And finally the resulted "housing demand shock" is given by

$$
\xi_{t}=\int_{0}^{\varepsilon_{\max }} \varepsilon\left[\ell_{t}+h_{t}(\varepsilon)\right]^{-\theta} f(\varepsilon) d \varepsilon+\frac{\kappa_{t}}{1-\kappa_{t}} \int_{\varepsilon_{t}^{*}}^{\varepsilon_{\max }} \varphi\left(\varepsilon_{t}-\varepsilon_{t}^{*}\right)\left[\ell_{t}+\frac{1}{1-\kappa_{t}}\right]^{-\theta} f(\varepsilon) d \varepsilon+\int_{0}^{\varepsilon_{\ell t}^{*}} \varphi\left(\varepsilon_{\ell t}^{*}-\varepsilon_{t}\right)\left[\ell_{t}\right]^{-\theta} f
$$


Notice in the special case with $\theta=0$, we have $\varepsilon_{\ell t}^{*}=\varepsilon_{t}^{*}$

$$
r_{h t}=\frac{\varphi}{\lambda_{t}} \int_{0}^{\varepsilon_{\max }} \varepsilon\left[\ell_{t}+h_{t}(\varepsilon)\right]^{-\theta} f(\varepsilon) d \varepsilon=\frac{\varphi}{\lambda_{t}} \int_{0}^{\varepsilon_{\max }} \varepsilon f(\varepsilon) d \varepsilon=\frac{\varphi}{\lambda_{t}}
$$

while the cutoff is determined by

$$
1-F\left(\varepsilon_{t}^{*}\right)=1-\kappa_{t}
$$

and $\xi_{t}$ becomes

$$
\xi_{t}=\varphi\left[1+\frac{\kappa_{t}}{1-\kappa_{t}} \int_{\varepsilon_{t}^{*}}^{\varepsilon_{\max }}\left(\varepsilon_{t}-\varepsilon_{t}^{*}\right) f(\varepsilon) d \varepsilon+\int_{0}^{\varepsilon_{t}^{*}}\left(\varepsilon_{t}^{*}-\varepsilon_{t}\right) f(\varepsilon) d \varepsilon\right]
$$

which is increasing in $\kappa_{t}$. The price equation becomes

$$
q_{t} \lambda_{t}=\beta E_{t} \lambda_{t+1} q_{t+1}+\xi_{t}
$$

Hence an increase in $\kappa_{t}$ will increases price and leaves the rents unchanged.

For a general case, we again assume power distribution again to maintain tractability. We have following system of equations

$$
\begin{gathered}
\left(\ell_{t}+\frac{1}{1-\kappa_{t}}\right) \varepsilon_{t}^{*-\frac{1}{\theta}} \varepsilon_{\max }^{-\eta} \frac{\varepsilon_{t}^{* \frac{1}{\theta}+\eta}-\varepsilon_{\ell t}^{* \frac{1}{\theta}+\eta}}{\frac{1}{\theta}+\eta}-\left[\left(\frac{\varepsilon_{t}^{*}}{\varepsilon_{\max }}\right)^{\eta}-\left(\frac{\varepsilon_{\ell t}^{*}}{\varepsilon_{\max }}\right)^{\eta}\right] \ell_{t}+\frac{1}{1-\kappa_{t}}\left[1-\left(\frac{\varepsilon_{t}^{*}}{\varepsilon_{\max }}\right)^{\eta}\right]=1 \\
\varepsilon_{\ell t}^{*}=\left(\frac{\ell_{t}}{\ell_{t}+\frac{1}{1-\kappa_{t}}}\right)^{\theta} \varepsilon_{t}^{*} \\
r_{h t} \lambda_{t}=\left[1+\frac{1}{\eta+1} \varepsilon_{\max }^{-\eta} \varepsilon_{t}^{* \eta+1}\right]\left[\ell_{t}+\frac{1}{1-\kappa_{t}}\right]^{-\theta}-\frac{1}{\eta+1} \varepsilon_{\max }^{-\eta} \varepsilon_{\ell t}^{* \eta+1} \ell_{t}^{-\theta}
\end{gathered}
$$

and

$$
\xi_{t}=\left[1+\frac{1}{\eta+1} \varepsilon_{\max }^{-\eta} \varepsilon_{t}^{* \eta+1}\right]\left[\ell_{t}+\frac{1}{1-\kappa_{t}}\right]^{-\theta}+\frac{\kappa_{t}}{1-\kappa_{t}}\left[1-\varepsilon_{t}^{*}+\frac{1}{\eta+1} \frac{\varepsilon_{t}^{* \eta+1}}{\varepsilon_{\max }^{\eta}}\right]\left[\ell_{t}+\frac{1}{1-\kappa_{t}}\right]^{-\theta}
$$




\section{REFERENCES}

Favilukis, J., S. C. Ludvigson, And S. VAn Nieuwerburgh (2016): "The Macroeconomic Effects of Housing Wealth, Housing Finance, and Limited RiskSharing in General Equilibrium," Journal of Political Economy, 125, 140-223.

Gertler, M. And S. Gilchrist (2018): "What Happened: Financial Factors in the Great Recession," Journal of Economic Perspectives, 32, 3-30.

IACOviello, M. AND S. NeRI (2010): "Housing Market Spillovers: Evidence from an Estimated DSGE Model," American Economic Journal: Macroeconomics, 2.

JordÀ, S., M. Schularick, AND A. M. TAYlOR (2016): "The great mortgaging: housing finance, crises and business cycles," 107-152.

JordA, O. (2005): "Estimation and Inference of Impulse Responses by Local Projections," American Economic Review, 95, 161-182.

Kaplan, G., K. Mitman, And G. Violante (2017): "The Housing Boom and Bust: Model Meets Evidence," Unpublished Manuscript.

Kiyotaki, N. And J. Moore (1997): "Credit Cycles," Journal of Political Economy, 105, 211-248.

Lagos, R. And R. Wright (2005): “A Unified Framework for Monetary Theory and Policy Analysis," Journal of Political Economy, 113, 463-484.

Landvoigt, T., M. Piazzesi, And M. Schneider (2015): "The Housing Market(s) of San Dieg," American Economic Review, 105, 1371-1407.

LiU, Z., P. Wang, And T. Zha (2013): "Land-Price Dynamics and Macroeconomic Fluctuations," Econometrica, 81.

Mian, A. And A. Sufi (2018): "Finance and Business Cycles: The Credit-Driven Household Demand Channel," Journal of Economic Perspectives, 32, 31-58.

Mian, A., A. Sufi, And E. Verner (2017): "Household Debt and Business Cycles Worldwide," Quarterly Journal of Economics, 132, 1755-1817.

Wen, Y. (2009): "An Analytical Approach to Buffer-Stock Saving under Borrowing Constraints," Federal Reserve Bank of St. Louis Working Paper 2009-026B.

Federal Reserve Bank of San Francisco, Hong Kong University of Science and Technology, Federal Reserve Bank of Atlanta, Emory University, and NBer 